\title{
CSDMS: a community platform for numerical modeling of Earth surface processes
}

\author{
Gregory E. Tucker ${ }^{1,2}$, Eric W. H. Hutton ${ }^{3}$, Mark D. Piper ${ }^{3}$, Benjamin Campforts ${ }^{3}$, Tian Gan ${ }^{3}$, \\ Katherine R. Barnhart ${ }^{1,2, a}$, Albert J. Kettner ${ }^{3}$, Irina Overeem ${ }^{2,3}$, Scott D. Peckham ${ }^{3}$, Lynn McCready ${ }^{3}$, and \\ Jaia Syvitski ${ }^{3}$ \\ ${ }^{1}$ Cooperative Institute for Research in Environmental Sciences (CIRES), University of Colorado Boulder, Boulder, CO, USA \\ ${ }^{2}$ Department of Geological Sciences, University of Colorado Boulder, Boulder, CO, USA \\ ${ }^{3}$ Institute for Arctic and Alpine Research (INSTAAR), University of Colorado Boulder, Boulder, CO, USA \\ ${ }^{\mathrm{a}}$ current address: Geologic Hazards Science Center, U.S. Geological Survey, Golden, CO, USA
}

Correspondence: Gregory E. Tucker (gtucker@ colorado.edu)

Received: 30 June 2021 - Discussion started: 13 July 2021

Revised: 3 January 2022 - Accepted: 6 January 2022 - Published: 17 February 2022

\begin{abstract}
Computational modeling occupies a unique niche in Earth and environmental sciences. Models serve not just as scientific technology and infrastructure but also as digital containers of the scientific community's understanding of the natural world. As this understanding improves, so too must the associated software. This dual nature - models as both infrastructure and hypotheses - means that modeling software must be designed to evolve continually as geoscientific knowledge itself evolves. Here we describe design principles, protocols, and tools developed by the Community Surface Dynamics Modeling System (CSDMS) to promote a flexible, interoperable, and ever-improving research software ecosystem. These include a community repository for model sharing and metadata, interface and ontology standards for model interoperability, language-bridging tools, a modular programming library for model construction, modular software components for data access, and a Python-based execution and model-coupling framework. Methods of community support and engagement that help create a communitycentered software ecosystem are also discussed.
\end{abstract}

\section{Introduction}

Our planet's surface is a dynamic place, changing on timescales from the momentary triggering of a landslide, to year-by-year resculpting of coastlines, to the formation of mountains and sedimentary basins over geologic time.
The challenge of living sustainably on a dynamic, humanimpacted planet is multi-faceted and multi-disciplinary and requires a deeper understanding of a diverse set of processes ranging from permafrost thawing to wildfire impacts, and from river delta sinking to changes in flooding. These interwoven research challenges have two things in common: they cross traditional boundaries of research, and their solution requires computational models and model-data integration. Meeting these challenges efficiently requires an effective, integrated, and holistic software cyber-infrastructure to support computational modeling and analysis across the environmental sciences. Models embody theory in a quantitative and algorithmic form. By performing calculations at blinding speed, numerical models extend our cognitive abilities, helping us explore and visualize the consequences of hypotheses. They allow us to apply existing theory to new situations. Where the processes are sufficiently understood, models can forecast potential trajectories of natural and anthropogenically perturbed Earth systems.

Creating, modifying, applying, and maintaining the software that implements numerical models requires time, money, and specialized skills. The software may be invisible, but its creation and maintenance constitute an infrastructure investment just as vital to science as the infrastructure supporting ship-based science or radio astronomy. More efficient infrastructure allows for more time devoted to other aspects of research and practice. Just as with laboratory infrastructure, scientific results that rely on software cyber- 
infrastructure are only as robust and reproducible as the software itself. Scientific software therefore needs quality control: errors in scientific software not only impede research but also can produce misleading results that lead to more serious consequences. The fact that modeling is both useful and technically challenging can give rise to a pernicious temptation: to use an inadequate model for the job simply because the code that implements it is more easily available or more usable than better alternatives (Addor and Melsen, 2019).

A modular community software infrastructure must therefore maximize flexibility, creativity, and reliability while minimizing technical overhead. To use an artistic analogy: an ideal modeling infrastructure should provide the geo-artist with a wide palette of colors, while making it easy to mix new ones, so that more time can be devoted to creating and less time to fussing with materials. Those materials must also be robust enough that the colors and textures will not degrade over time.

Here we describe software tools, standards, and practices that are designed to enhance research productivity by reducing the "time to science" in Earth modeling. Such tools and concepts form the key elements behind the Community Surface Dynamics Modeling System (CSDMS). Founded in 2007 with major support from the US National Science Foundation, CSDMS is a facility that supports and promotes computational modeling of diverse Earth surface processes in domains that span geomorphology, sedimentology, stratigraphy, marine geology, and hydrology and related aspects of geodynamics, geochemistry, soils, ecosystems, and human dimensions. CSDMS is currently organized into 12 community interest groups, representing about 2000 members, and a small (about six full-time-equivalent positions) Integration Facility that manages a web portal, develops middleware, and coordinates community events and resources. Here we present tools and standards developed by and for the CSDMS community. We describe a set of effective engineering practices that are well known among professional software developers but less known among geoscientists and environmental scientists. We highlight aspects of the human element: community engagement and education turn out to be key elements in forging a shared and ever-improving computational ecosystem.

We start with a background review of issues in scientific computing and research software across the sciences (Sect. 2) and a brief history of CSDMS (Sect. 3). Section 4 frames the operational tasks involved in numerical process modeling as a six-fold spectrum, ranging from simply executing a model program to building a complete model from scratch. This sets the stage for a review of tools and practices designed to make these various tasks more efficient and their products more sustainable through sharing, standardization, education, and a set of enabling tools (Sects. 6-7). We conclude with a discussion of opportunities, needs, and challenges (Sect. 8).

\section{Background}

\subsection{Scientific computing is here to stay}

Computing has emerged as a pillar of scientific inquiry, alongside theory, experimentation, and direct observation (Reed et al., 2005). The ability to perform calculations at speeds that would have astonished researchers of our grandparents' generation continues to open up new territory across the sciences and allows us to probe the limits of predictability in natural and engineered systems (Post and Votta, 2005; Post, 2013). Computing, and the software that supports it, underlies numerous recent success stories, from improved hurricane forecasting to the imaging of black holes.

Within the sphere of computing, numerical modeling - defined here as the computing of solutions to a set of equations and algorithms that represent a system - plays a central role. The process of formulating a computational model and the theory behind it encourages deep and precise thinking (e.g., Guest and Martin, 2020). Computational models both encapsulate theory and provide machinery with which to explore the consequences of that theory. Pipitone and Easterbrook (2012), for example, described climate models as "executable theories of climate". Numerical models in Earth and environmental science embody executable theory for many different aspects of the natural world (Fig. 1). At the same time, the numerical algorithms and the software that implement them provide a kind of mind-enhancing machinery. Whereas other scientific technology extends our senses - allowing us to "see" what lies beyond the visible spectrum and to "feel" the vibrations in the Earth - computational modeling extends our cognitive capacity. By turning ideas into algorithms, we gain the ability to explore the logical consequences of our ideas, make predictions, and compare them with observations. Discovery comes not only when the calculations provide self-consistent explanations for otherwise mysterious phenomena, but especially when the calculations surprise us, revealing a logic trail that leads to new insights (Bras et al., 2003).

With the rapid growth in computing and digital infrastructure, many scientists now devote a large fraction of their research time to developing software (Hannay et al., 2009; Prabhu et al., 2011; Wilson et al., 2014; Singh Chawla, 2016; Pinto et al., 2018). A survey of nearly 2000 researchers in 40 countries by Hannay et al. (2009) revealed that $84 \%$ of respondents considered software development important for their research. According to their findings and those of Prabhu et al. (2011), scientists spend as much as a third of their time writing and debugging computer programs. In the geosciences software has become critical research infrastructure that is as vital and worthy of maintenance as ships, telescopes, and seismographic arrays. Yet the invisibility of software has led to challenges in developing and sustaining this critical research infrastructure (Eghbal, 2016). 


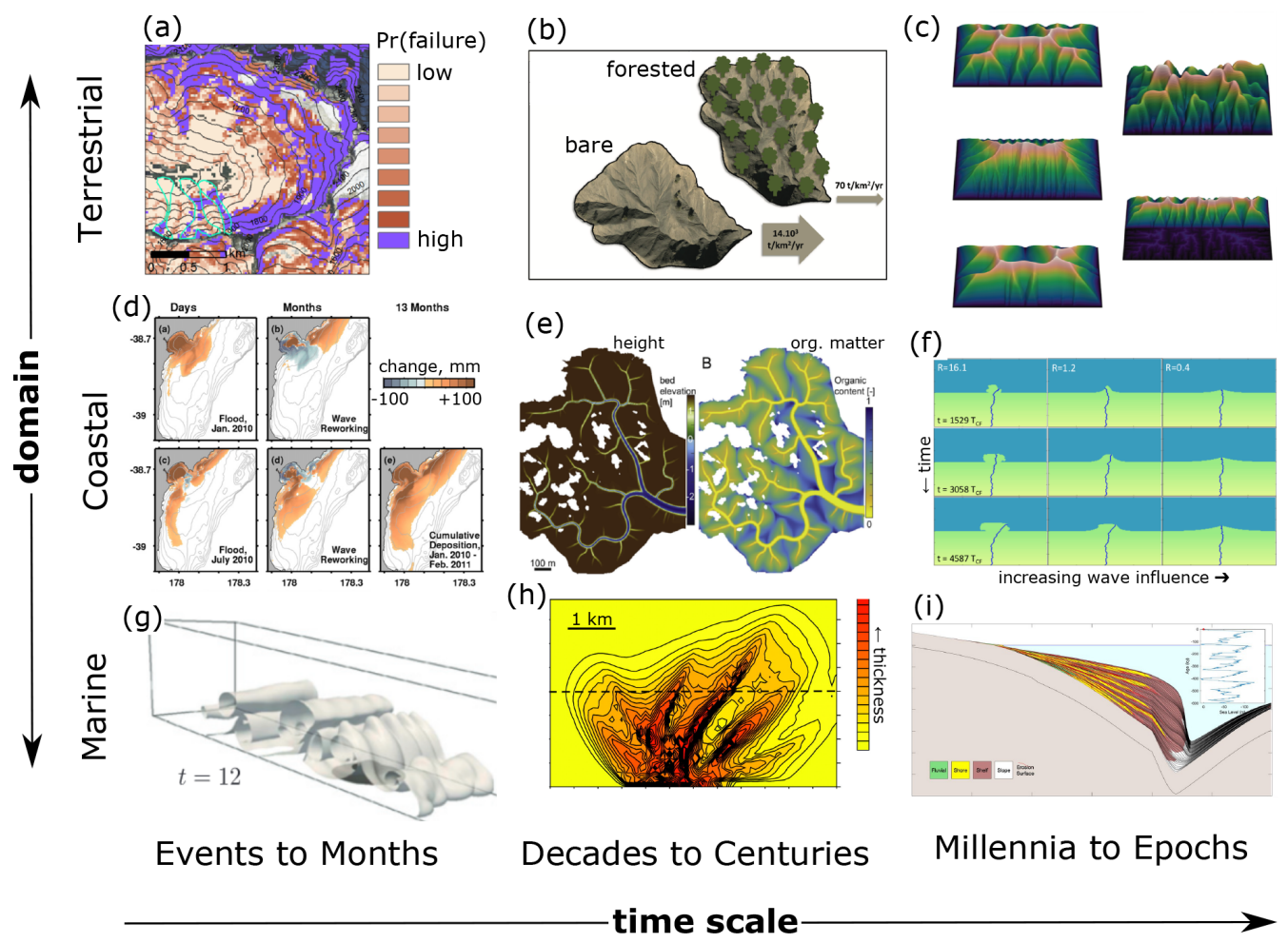

Figure 1. Examples of Earth surface process models across a variety of domains and timescales, here focusing on models of sedimentary processes: (a) probabilistic landslide occurrence (Strauch et al., 2018), (b) catchment sediment yield (Carriere et al., 2020), (c) landform evolution (Barnhart et al., 2019), (d) coastal and shelf dispersal of fluvially derived sediment (Kuehl et al., 2016), (e) salt marsh evolution under tidal and sea level forcing (Mariotti, 2018), (f) delta evolution as a function of river and wave forcing (Ratliff et al., 2018), (g) turbidity current dynamics (Nasr-Azadani et al., 2013), (h) submarine turbidity fan stratigraphy (Groenenberg et al., 2010), and (i) sequence stratigraphy (Steckler et al., 2019).

\subsection{Growing pains}

Experimental science absolutely depends on having highquality laboratory infrastructure and operating it with careful, systematic protocols. In this respect, computational science differs only in the invisibility of its primary infrastructure. Experimental research methods, with their emphasis on transparency and replicability, pre-date computational science by over 200 years (Wilson, 2006; Fomel and Claerbout, 2009), and so it comes as no surprise that computational science has experienced growing pains. Errors in software can have serious consequences for research. Software faults led to the failure of the Arianne rocket in 1996 and of the Mars Climate Orbiter mission in 1999. In 2006, discovery of a bug in image-processing software led to the retraction of five papers in computational biochemistry (Miller, 2006). High-profile cases like these have sparked concern about the quality and reliability of research software. Studies of scientific software development practices underscore these concerns, suggesting that the practice of formal testing of code correctness remains relatively limited (Post and Votta, 2005; Wilson, 2006; Hannay et al., 2009; NguyenHoan et al., 2010; Clune and Rood, 2011; Howison and Herb- sleb, 2011; Prabhu et al., 2011; Kanewala and Bieman, 2014; Heaton and Carver, 2015). Hatton (1997) evaluated the performance of a collection of seismic data processing programs and found that the results varied even among programs that claimed to use the same algorithm. Seeing little evidence of progress 10 years later, Hatton (2007) worried that foundations for scientific software would remain weak if the community persisted in "building scientific castles on software sands when we could do so much better".

However, serious flaws in scientific software are not inevitable. Pipitone and Easterbrook (2012) found, for example, that climate models, which are subject to rigorous testing and quality controls, have very low defect density as compared with other open-source software of similar scale. Their findings show that software quality control practices can work well when applied to research products. So why are such practices not used more widely? One common obstacle is simply a lack of awareness of, and training in, effective quality-control practices such as unit testing and continuous integration (Wilson, 2006; Faulk et al., 2009; Hannay et al., 2009; Kanewala and Bieman, 2014), a finding that led Faulk et al. (2009) to remark that "scientists are trained to man- 
age threats to validity in experimental design but not in their codes".

A related challenge lies in computational reproducibility: the ability to recreate the results of a study using the same data and software. The ability to reproduce others' findings forms a cornerstone of the scientific method. Yet as computational science has bloomed, concern has grown over the difficulty or impossibility of reproducing published results (e.g., Schwab et al., 2000; Peng, 2011; Stodden et al., 2013; Barba, 2016; AlNoamany and Borghi, 2018; Chen et al., 2019; Krafczyk et al., 2019). In the words of LeVeque (2009), "scientific and mathematical journals are filled with pretty pictures of computational experiments that the reader has no hope of repeating". In a reproducibility study of 306 articles in the Journal of Computational Physics, Stodden et al. (2018) found only six that provided enough method information to re-run the analysis without help from the original authors. Of the remaining papers, about half were impossible to reproduce even after contacting the authors for assistance.

Reproducibility has several dimensions: sharing (the digital artifacts need to be available), discoverability (one needs to be able to find them), learnability (there needs to be sufficient documentation), and operability (the operating interface needs to be familiar, and the correct computational environment and dependencies must be available). Failure in any of these dimensions hurts productivity because researchers end up spending more time either figuring out opaque, poorly documented software or reinventing their own version from scratch. Collectively, reports of non-reproducible results and unsustainable, under-tested software suggest that computational science relies on a brittle cyber-infrastructure, and productivity suffers as a result (Wilson, 2006; Faulk et al., 2009; Prabhu et al., 2011).

A variety of factors contribute to the challenges of research software quality, reproducibility, and reusability. Most scientists lack formal training in software development and tend not to know about tools and practices that could increase their productivity (Kelly, 2007; Basili et al., 2008; Faulk et al., 2009; Hannay et al., 2009; Hwang et al., 2017; AlNoamany and Borghi, 2018; Pinto et al., 2018; Kellogg et al., 2018). Incentives also play a role: the academic system rewards publication of new results rather than production of high-quality, reusable software (though credit mechanisms for software are now starting to emerge) (LeVeque, 2009; Howison and Herbsleb, 2011; Morin et al., 2012; Turk, 2013; Ahalt et al., 2014; Poisot, 2015; Hwang et al., 2017; Wiese et al., 2019). The combination of incentive structure and lack of training in best practices can lead to inflexible, hard-to-maintain software (Brown et al., 2014; Johanson and Hasselbring, 2018). Often enough it ends up as "abandonware" when a project ends (Barnes, 2010). Reluctance by code authors to provide pro bono support also plays a role. A certain embarrassment factor may contribute: in our own experience, as well as reports from other fields, researchers often express reluctance to share "messy" code, even when they have used the software as the basis for published research (Barnes, 2010; Morin et al., 2012; LeVeque, 2013).

\subsection{New community practices}

Despite the growing pains, there are solutions on the horizon. Tools and practices already exist that can improve the quality and efficiency of software cyber-infrastructure, and improve productivity through coordination and reuse. Practices, tools, and techniques that the software community uses routinely have begun to see uptake in the sciences, with good success (Bangerth and Heister, 2013; Turk, 2013; Hastings et al., 2014; Wilson et al., 2014; Brown et al., 2014; Poisot, 2015; Hwang et al., 2017; Nanthaamornphong and Carver, 2017; Scott, 2017; Taschuk and Wilson, 2017; Wilson et al., 2017; Benureau and Rougier, 2018; Bryan, 2018; Adorf et al., 2018; Lathrop et al., 2019); in Sect. 3, we describe how the CSDMS community has implemented some of these. While there remains a critical need for teaching and training in scientific computing, some universities, as well as community organizations such as Software Carpentry and various domain-centered groups (including CSDMS), have begun to fill that niche (e.g., Jacobs et al., 2016).

One promising development is the emergence of software journals, which provide a mean to reward research software with the academic credit it deserves. For example, the Journal of Open Source Software (JOSS), which began publishing in May 2016, focuses not on papers about results obtained by software, but instead on the "full set of software artifacts" (Smith et al., 2018). Reviewers of JOSS submissions evaluate the software in terms of criteria such as installation, functionality, documentation, example of usage, and testing. A short abstract describing the purpose and function of package forms the only textual component of a JOSS publication. For the Earth and environmental sciences, JOSS now complements more traditional text-based journals (like this one) that provide a forum for software-oriented issues such as algorithm development and model verification. The growing importance of software in research has also led to a new type of career track: research software engineers (RSEs), whose cross-training in computing and domain science positions them to help researchers build and maintain highquality, sustainable software (Baxter et al., 2012). Thus, the academic world now has the beginnings of a credit mechanism that incentivizes high-quality research software cyberinfrastructure and the first glimmers of a professional structure to help create and maintain that cyber-infrastructure.

Better incentives and support for writing, documenting, and publishing research software can help address the productivity problem because they encourage software reuse over reinvention. Community software libraries and modular frameworks provide another avenue for reuse. Libraries are already widely available for general tasks such as numerical computing, parallel programming, and general science and engineering operations; some examples include PETSc 
(Balay et al., 1997, 2015a, b), deal.II (Arndt et al., 2021b, a), and the SciPy family (Virtanen et al., 2020). "Librarization" of software makes it easier to share, reuse, and maintain (Brown et al., 2014). Frameworks are defined as a collection of interoperable modules together with an environment for running and combining them. A framework provides a way to create coupled numerical models and more generally to simplify computational workflows (e.g., Leavesley et al., 1996; Voinov et al., 2004; Peckham et al., 2013). Frameworks, as well as some open-source libraries, take advantage of contributions from many different community members: the software becomes a resource created by and for a scientific community. Growth of a community framework does not happen by accident, however. Case studies of community frameworks, libraries, and other software packages reveal that success requires two elements: a thoughtful, deliberate approach to community engagement (Bangerth and Heister, 2013; Turk, 2013; Lawrence et al., 2015), and carefully designed standards and protocols (Peckham et al., 2013; Harpham et al., 2019).

\section{A community-based modeling system for Earth surface processes}

The opportunities and growing pains that face scientific computing generally also apply to the sciences that deal with the Earth's surface. To embrace these opportunities, the CSDMS Integration Facility was launched in 2007 with a mission to accelerate the pace of discovery in Earth-surface processes research. The centerpiece was envisioned as "a modeling environment containing a community-built, freely available suite of integrated, ever-improving software modules aimed at predicting the erosion, transport, and accumulation of sediment and solutes in landscapes and sedimentary basins over a broad range of time and space scales" (Anderson et al., 2004). A key concept is that a modular, community-built modeling system not only opens new opportunities for using coupled models to explore the interactions among processes that were once considered in isolation but also increases productivity by lowering the kinds of barriers described earlier. Achieving this requires a combination of the following elements.

- community, including coordination, sharing, communication, and collaboration (e.g., conferences, workshops, hackathons);

- computing, including software tools, standards, templates, and access to high-performance computing and cloud resources;

- education, including in-person and online resources for learning tools, techniques, and best practices and resources for teaching these to others.

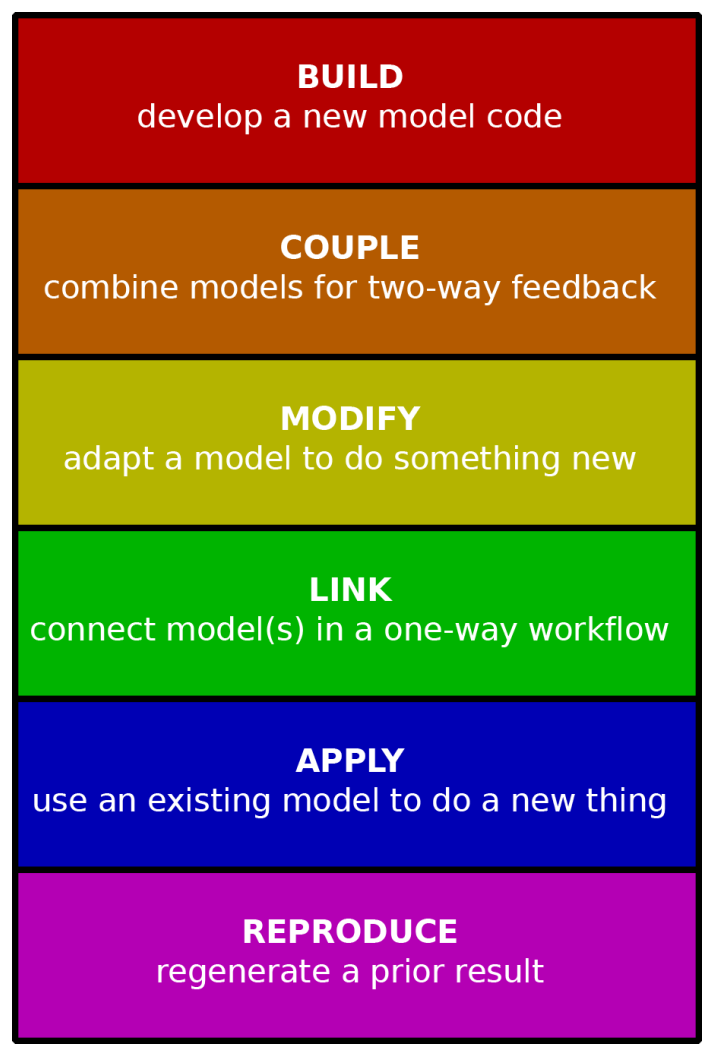

Figure 2. Taxonomy of model operation tasks. Tasks are listed in (approximately) increasing order of complexity from bottom to top. The most basic procedure involves executing a model with preexisting inputs to reproduce a prior calculation, whereas building a new code requires program design, development, documentation, and testing.

In the following sections, we describe the software technology, community building, and education elements developed by CSDMS and how they help mitigate the obstacles discussed in Sect. 2. A useful way to understand the purpose of these products and activities is to consider the different modes in which researchers operate numerical models and the opportunities that these different modes present to increase efficiency and productivity.

\section{A taxonomy of model operation}

What tasks are often required in computational modeling? How might those tasks be made efficient? Here we identify six types of model-related activity, each of which has a unique set of challenges. Inspired by Bloom's Taxonomy of cognitive learning tasks, these six activities are arranged in order of complexity. The six modeling modes are summarized in Fig. 2. 


\subsection{Reproducing}

The most basic operation of a numerical model is to run it with predefined inputs. This is often the first step in learning how to use a particular model. The ability to reproduce a model calculation efficiently involves all four of the FAIR principles (findable, accessible, interoperable, reproducible) (Wilkinson et al., 2016; Lamprecht et al., 2020; Katz et al., 2021; Chue Hong et al., 2021). The user must be able to find and access the right version of the software. The user needs to learn how to execute the model: a task made easier if the program follows an interoperability standard. In order to reproduce the prior calculation, the user must have access to the input data and must be able to recreate a compatible execution environment, including whatever dependencies might be needed.

\subsection{Applying}

To use a computational model in a new application, a user needs to understand the theory and algorithms behind it, which requires good documentation. In addition, operating the model involves creating new input data and often executing various pre-processing operations to derive the right kind of inputs. Sometimes it also requires setting up a grid mesh. In some cases, mesh generation is a major undertaking, for example, meshes for 2D storm-surge models such as ADCIRC (Luettich et al., 1992) and 3D regional ocean circulation models such as ROMS (Shchepetkin and McWilliams, 2005) are time-intensive to set up.

\subsection{Linking}

Here linking means operating a model as part of a sequential workflow. For example, the workflow might include preprocessing data, using those data as input to the execution of a model, using the output as input to another model, and/or performing additional operations on the model's output. To link a model in this way requires, among other things, compatibility in data formats. Any incompatibility between the outputs from one step and the inputs to the next means someone has to write code to do the appropriate translation.

\subsection{Modifying}

When a model provides most but not all of the functionality needed for a particular application, the would-be user faces a choice: modify the existing program or write a new one that fits the purpose. Modifying an existing model program can save a lot of duplication of effort, but this is only true when the model package includes good internal documentation, a modular design, and a structure that allows for modifications and enhancements while preserving the original functionality. A standard interface design can help by providing a familiar structure.

\subsection{Coupling}

Many of the exciting research frontiers in Earth and environmental science lie at the seams between systems. Some examples include rivers and coasts (e.g., Ratliff et al., 2018); tectonics and Earth surface processes (e.g., Roy et al., 2016); ecosystem, soil, and landscape evolution (e.g., Istanbulluoglu and Bras, 2005; Pelletier et al., 2017; Lyons et al., 2020); permafrost and hydrology; and human actions and biophysical systems (e.g., Robinson et al., 2018). For these sorts of problems, coupled numerical modeling provides a great way to develop insight and to test hypotheses by comparing models with observations. The complexity of the task of coupling two numerical models depends on the nature of coupling (for example, sequential execution within each time step versus coupling via joint matrix inversion) and on the program structure of each. The task becomes much simpler when both models offer a public, standardized interface: a set of callable functions that allow the appropriate exchange of data and mutual execution of algorithms.

\subsection{Building}

New ideas stimulate the need for new models. It is a healthy sign of growth when a scientific community produces lots of new models because it signifies rapid development and exploration of new concepts. Writing a numerical model program from scratch can be a time-consuming exercise. Libraries of pre-existing functions and data structures can greatly simplify the task. Most modern programming languages offer libraries to handle basic mathematical operations, but even with these available model-building can be a major effort.

The job becomes easier when the developer can draw on component libraries that provide data structures and algorithms to address common tasks in numerical modeling, such as grid setup and input/output. It becomes easier still when common domain-specific algorithms have been librarized and made available as building blocks with a standard interface (e.g., Brown et al., 2014). Below we will look at an example of a component library that was designed specifically for building numerical models.

\section{The CSDMS model repository: a platform for sharing and archiving software resources}

Not so long ago, making model source code freely available was more the exception than common practice. Model developers tended to view their models as trade secrets. If others wanted to use a model, the developer needed to be contacted, and could negotiate to become more involved in the research. Furthermore, fewer tools and platforms were available to promote sharing, like GitHub (established 2008) or SourceForge (established 1999). 
Science clearly benefits from openly shared source code. For one, sharing reduces duplication. After all, there is less need to write a model from scratch once a model has proven to capture a certain process well. Therefore, sharing of source code accelerates science, as others are on a faster trajectory to learn from and build upon previous model development efforts. Sharing of source code also makes science more robust and trusted, as people can report and fix bugs. Reproducing computational results requires shared digital files (either executable binary files or source code; ideally the latter so that the algorithms are transparent). It is therefore encouraging to see a modeling culture shift over the last 2 decades (e.g., Hsu et al., 2015). For good data management, there are now the FAIR principles - findability, accessibility, interoperability, and reusability - that have been formulated as guidelines for data producers and publishers (Wilkinson et al., 2016). According to the FAIR principles, each dataset should be assigned a unique persistent identifier such as a digital object identifier (DOI), along with searchable metadata. By including a formal, broadly applicable representation language and using open and widely accepted domain-relevant vocabularies and ontologies, datasets become more interoperable. In addition, by providing an abundance of documents that describe datasets and how they can be used, including license information, data become more reusable.

The FAIR principles can be applied to research software, albeit with modifications that account for the unique aspects of software (for example, unlike most forms of digital data, software is executable) (Lamprecht et al., 2020; Katz et al., 2021; Chue Hong et al., 2021). For model code, versioncontrol platforms are now more widely used for sharing source code, which helps enable findability and accessibility. But as the FAIR principles indicate, sharing code by itself is not enough. Therefore, CSDMS implemented the FAIR principles in setting up a model repository for Earth surface dynamics (Fig. 3). A minimal set of metadata parameters is defined to describe a model, provide contact information for the model development team, indicate technical details such as operating platform and the software license, describe the model input and output, list its processes and key physical parameters, and indicate limitations. This minimal set of metadata includes a link to the actual source code, which needs to be made available all the time through a personal web repository or through the CSDMS community repository. All model metadata stored on the CSDMS web server, as well as the actual source code (when stored in the CSDMS code repository on GitHub), are accessible for machines through web application programming interfaces (APIs). This makes it possible to automatically find and use the model. DOIs for stable versions of any listed code are generated on request and included with the metadata. Model metadata are enriched by including additional reference information, such a comprehensive bibliography. Following this practice, the CSDMS model repository currently holds 387 open-source models of the community (as of February 2021). The models and tools in the repository span a range of languages, with Python, C, and Fortran being the most popular (Fig. 4). The diversity of languages raises a challenge in creating an interoperable framework. We will return to this point and look at one solution in Sect. 6.2.

\section{The CSDMS Workbench}

The CSDMS Workbench is a suite of tools, standards, documents, and resources that collectively provide a modular environment for model execution, analysis, and model-data integration. The Workbench comprises six main elements:

1. the Basic Model Interface (BMI), an interface standard that simplifies model execution and coupling (Hutton et al., 2020a; Peckham et al., 2013);

2. babelizer, a language-bridging tool that adds a Python interface to BMI-enabled model programs written in various other languages;

3. the Python Modeling Toolkit (pymt), a Python-language execution and model-coupling environment that includes utilities for grid mapping and other operations, together with a set of model components;

4. data components, which are small Python-language modules that use the BMI to fetch data from particular datasets;

5. Landlab, a component-based Python library for model building and sharing of interoperable components (Hobley et al., 2017; Barnhart et al., 2020a);

6. Standard Names, which is an ontology standard for naming variables.

In the following we give a brief description of each of these elements and how they combine to form a modular modeling system.

\subsection{The Basic Model Interface (BMI) standard}

When you sit in the driver's seat of an unfamiliar car, you're presented with a familiar sight: whatever the make or model, the vehicle provides a steering wheel, brake pedal, and speedometer. Although we do not usually think of it this way, drivers across the globe benefit from a standard interface - a set of control mechanisms and information displays that have essentially the same design regardless of whether the car is a tiny electric two-seater vehicle or a giant stretch limousine. This standard interface makes operating a car much easier than if each vehicle presented a radically different interface. Imagine a world where switching from a sports car to a pickup truck required months of study and practice!

We believe numerical models should offer a similar standardization. To this end, CSDMS developed the Basic Model 


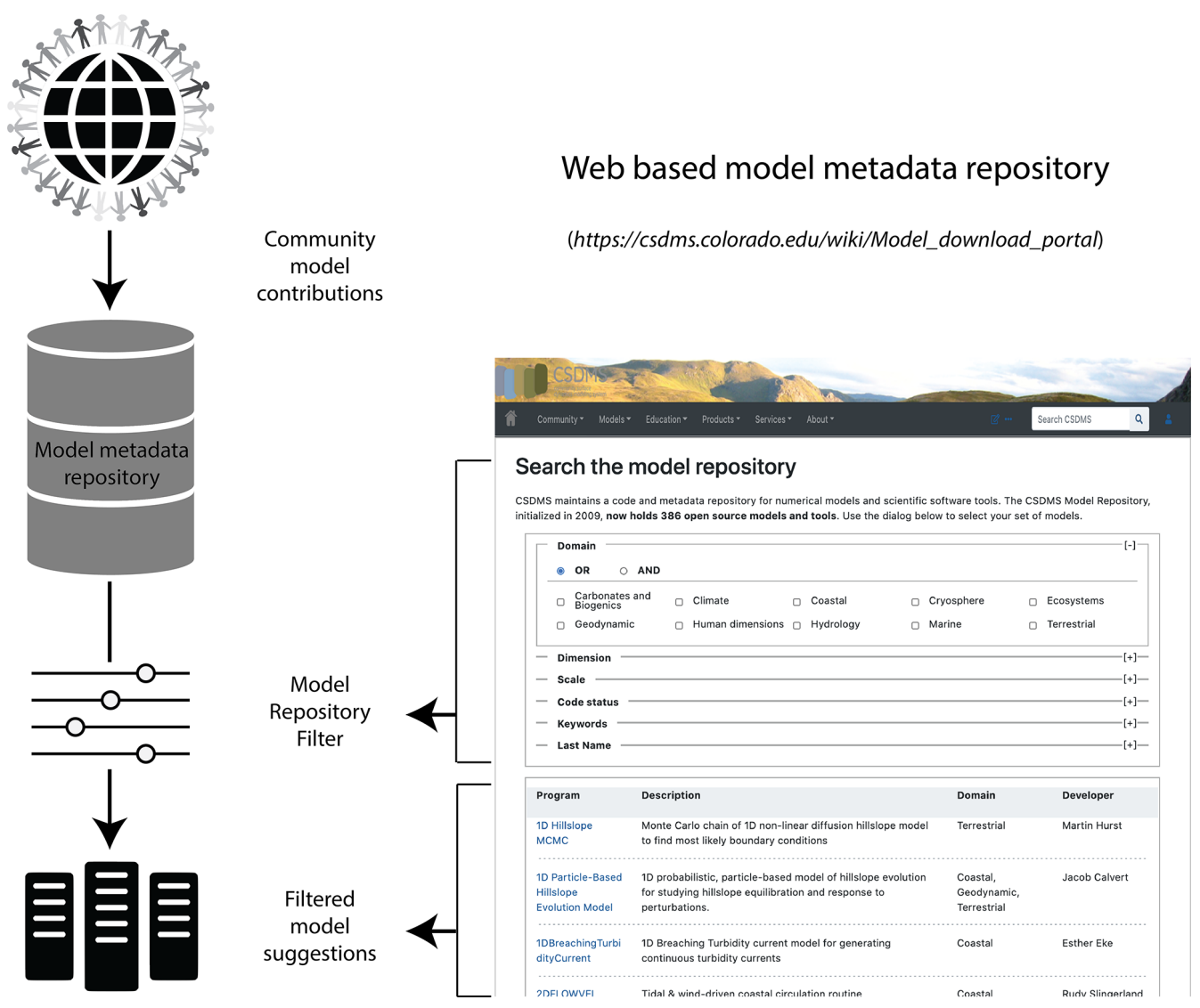

Figure 3. Schematic illustration of the CSDMS model repository. Community-contributed model codes are supplied with extensive metadata collected as part of the contribution process. These metadata allow repository users to filter their searches according to various criteria. An example of the filtered-search interface is shown at right.

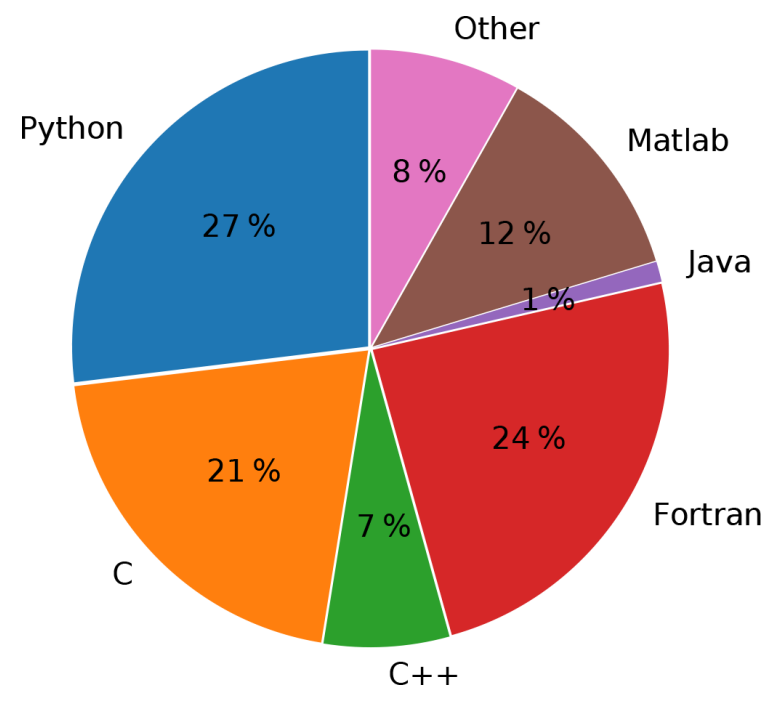

Figure 4. Distribution of different languages used by models and tools in the CSDMS model repository (percentages out of 453 total programs; not weighted by program size).
Interface (BMI) (Peckham et al., 2013; Hutton et al., 2020a). In software engineering, an interface is a named set of functions with prescribed arguments and return values. The BMI provides a standard set of functions for querying and controlling a model. Just as with a car, when a model is equipped with a BMI, it becomes easier to use because its control functions are now the same as every other model with a BMI.

Further, because BMI includes variable-exchange functions, a model with a BMI can be coupled with other models that expose a BMI. Tables 1 and 2 list the individual functions that comprise the Basic Model Interface, along with a brief description of each. The table shows the current version of BMI, version 2.0, which represents a collection of improvements to the original specification, especially in the representation of model grids (Hutton et al., 2020a). A model program that has been wrapped with a BMI can function as an interoperable component, which can be combined with others to create integrated models (Fig. 5).

While a BMI can be written for any language, CSDMS currently supports four languages: $\mathrm{C}, \mathrm{C}++$, Fortran, and Python. A simple example of using a BMI written in Fortran is shown in Listing 1. 
Table 1. Listing and description of Basic Model Interface (BMI) functions for run control and data access.

\begin{tabular}{ll}
\hline Function Name & Description \\
\hline initialize & Perform startup tasks for the model. \\
update & Advance model state by one time step. \\
update_until & Advance model state until the given time. \\
finalize & Perform tear-down tasks for the model. \\
get_component_name & Name of the model. \\
get_input_item_count & Count of a model's input variables. \\
get_output_item_count & Count of a model's output variables. \\
get_input_var_names & List of a model's input variables. \\
get_output_var_names & List of a model's output variables. \\
get_var_grid & Get the grid identifier for a variable. \\
get_var_type & Get the data type of a variable. \\
get_var_units & Get the units of a variable. \\
get_var_itemsize & Get the size (in bytes) of one element of a variable. \\
get_var_nbytes & Get the total size (in bytes) of a variable. \\
get_var_location & Get the grid element type of a variable. \\
get_current_time & Current time of the model. \\
get_start_time & Start time of the model. \\
get_end_time & End time of the model. \\
get_time_units & Time units used in the model. \\
get_time_step & Time step used in the model. \\
get_value & Get a copy of values of a given variable. \\
get_value_ptr & Get a reference to the values of a given variable. \\
get_value_at_indices & Get variable values at specific locations. \\
set_value & Set the values of a given variable. \\
set_value_at_indices & Set the values of a variable at specific locations. \\
\hline &
\end{tabular}

Table 2. Listing and description of Basic Model Interface (BMI) functions for querying grid data.

\begin{tabular}{ll}
\hline Function Name & Description \\
\hline get_grid_rank & Get the number of dimensions of a computational grid. \\
get_grid_size & Get the total number of elements of a computational grid. \\
get_grid_type & Get the grid type as a string. \\
get_grid_shape & Get the dimensions of a computational grid. \\
get_grid_spacing & Get the spacing between grid nodes. \\
get_grid_origin & Get the origin of a grid. \\
get_grid_x & Get the locations of a grid's nodes in dimension 1. \\
get_grid_y & Get the locations of a grid's nodes in dimension 2. \\
get_grid_z & Get the locations of a grid's nodes in dimension 3. \\
get_grid_node_count & Get the number of nodes in the grid. \\
get_grid_edge_count & Get the number of edges in the grid. \\
get_grid_face_count & Get the number of faces in the grid. \\
get_grid_edge_nodes & Get the edge-node connectivity. \\
get_grid_face_edges & Get the face-edge connectivity. \\
get_grid_face_nodes & Get the face-node connectivity. \\
get_grid_nodes_per_face & Get the number of nodes for each face.
\end{tabular}

The model shown in this example is the surface water component of the Precipitation Runoff Modeling System (PRMS), developed by the U.S. Geological Survey (Leavesley et al., 1983). In the example, the model is initialized from its native configuration file, then stepped forward in time until it reaches its stop time, whereupon any resources it uses are deallocated. Note that only BMI function calls are used to drive the model; no knowledge of the underlying calls to control PRMS is needed.

Hoch et al. (2019) provide a current research example of using BMI. In their study, they coupled a hydrologic model, PCR-GLOBWB, with a pair of hydrodynamic mod- 


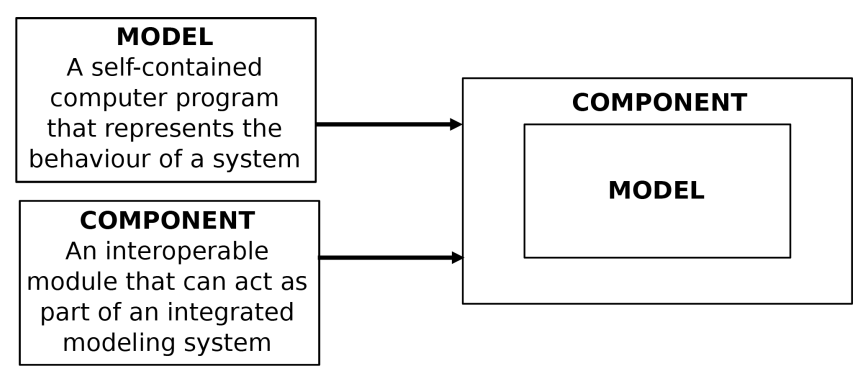

Figure 5. When a numerical model program is "wrapped" with a standard interface and compiled as an importable module, it becomes an interoperable component.

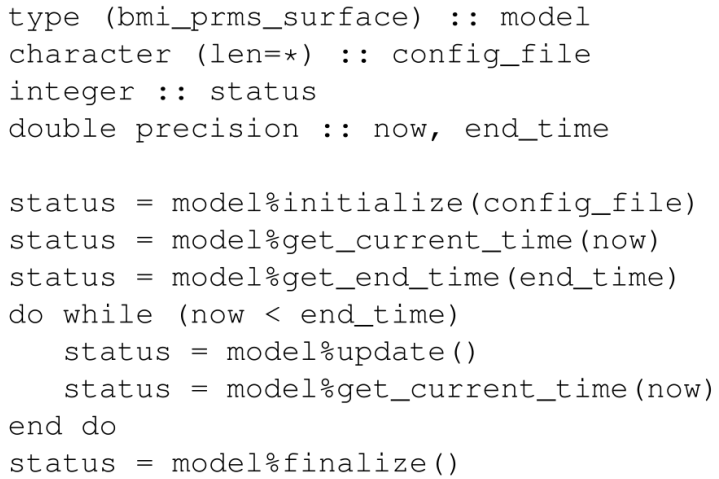

Listing 1. Example Fortran BMI code.

els, CaMa-Flood and LISFLOOD-FP, through BMI. They observed that a coupled model system enhanced the accuracy of peak discharge simulations (Fig. 6).

Hoch et al. (2019) conclude that "results confirm that model coupling can indeed be a viable way forward towards more integrated flood simulations. However, results also suggest that the accuracy of coupled models still largely depends on the model forcing".

\subsection{Language interoperability: the babelizer}

Looking at Fig. 4, we notice that software generated by the CSDMS community reflects a range of programming languages, and thus language interoperability is critical to a coupling framework if it is to bring together this diverse set of models.

One approach to solving this problem is to choose a hub language through which other languages will communicate. Other approaches include that used by the Common Component Architecture and the babel compiler (Epperly et al., 2012), where bridges are built from one language directly to every other language, and eWaterCycle through gprc4bmi where models communicate through the network ports of software containers (Hut et al., 2021). An advantage of this approach is that it needs only to provide bridges from each supported language to the hub language, rather than building bridges for each language to every other language. CSDMS uses Python as a hub language for several reasons: it is open source, has a large user base in the user community, and has an active community that supports a vast library of third-party packages (numpy, scipy, xarray, pandas, etc.), and importantly there are existing pathways to bring many other languages into Python.

The babelizer is a command-line utility CSDMS created to streamline the process of bringing a BMI component into Python. For libraries that expose a BMI, the babelizer creates the necessary glue code to create a Python-importable package that presents the BMI component as a Python class. We wrote the babelizer to be easily extensible to additional languages, but presently it can be used to wrap libraries written in $\mathrm{C}, \mathrm{C}++$, and Fortran using the Cython language.

\subsection{Execution and coupling framework: pymt}

Models in the Earth sciences are as diverse as the environments they are intended to represent. Codes are written by hundreds of authors, in different languages, and from a diverse range of domains; operate on timescales and space scales that span orders of magnitude, and are oftentimes written in isolation - never intended for use by someone outside the core development team. For these reasons models do not fit so neatly together.

Although the CSDMS collection of models is incredibly diverse, there is a common thread possible - the Basic Model Interface (BMI; Sect. 6.1) - which connects them and allows us to create tools that allow scientists to easily pick up, run, and even couple these models with one another. While only a subset of codes in the Model Repository (Sect. 5) provide a BMI, the concept is general enough that any model can be given one. To provide a framework for operating and coupling these BMI-equipped codes, the CSDMS Integration Facility develops and maintains a Python package known as the pymt (Python Modeling Toolkit).

The CSDMS Integration Facility has written the pymt as a Python package that gives scientists a set of utilities for running and coupling Earth system models within a Python environment. We primarily see the pymt as two things: (1) a collection of Earth surface models, in which every model exposes a standardized interface (and thus if you are able to run one model, you will be able to run any model), and (2) tools needed for coupling models across disparate time and space scales. A key feature of pymt is extensibility. Any contributor can implement a BMI and use the babelizer (6.2) to create to add a new model or utility to the toolkit.

Although the pymt itself is written in Python, the models in its collection need not be written in Python. The babelizer allows developers and contributors to bring models from other languages into a Python environment. The current pymt model collection is detailed in Table 3. One thing 


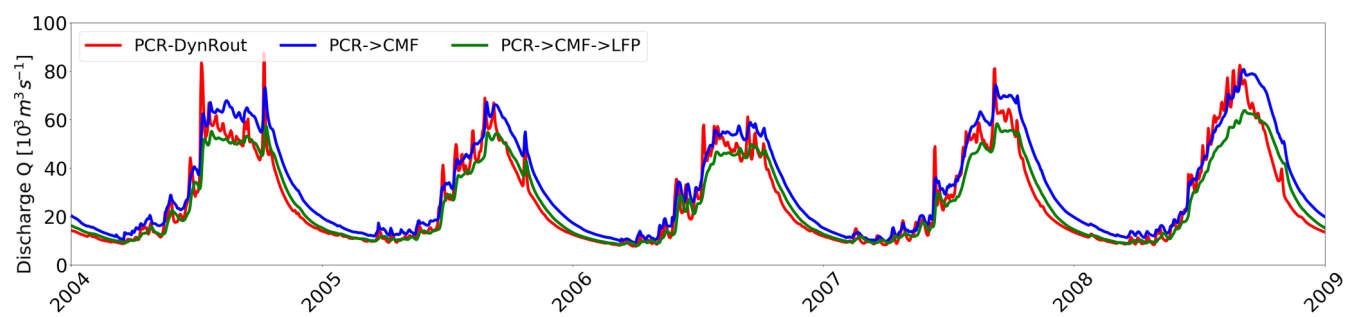

Figure 6. Simulated discharge at a river monitoring station from coupled hydrologic and hydrodynamic models (reproduced from Fig. 6 in Hoch et al., 2019).

Table 3. Models available as components in the Python Modeling Tool pymt.

\begin{tabular}{lll}
\hline Component & Property/process(es) & Language \\
\hline FrostNumber & permafrost occurrence & Python \\
Kudryavtsev $(\mathrm{Ku})$ & soil active layer thickness & Python \\
GIPL & soil temperature and heat flow & Fortran \\
ECSimpleSnow & snow balance & Fortran \\
HydroTrend & river water and sediment discharge & C \\
RAFEM & river avulsion and floodplain evolution & Python \\
CHILD & landscape evolution & C++ \\
CEM & sandy, wave-dominated coastline evolution & C \\
GridMet & meteorological data access & Python \\
sedflux3D & seafloor evolution & C \\
Avulsion & river avulsion & C \\
Plume & hypopycnal sediment plume & C \\
Subside & 2D lithospheric flexure & C \\
OverlandFlow* & surface water runoff & Python \\
Flexure* & 1D and 2D lithospheric flexure & Python \\
LinearDiffuser* & 2D linear diffusion & Python \\
ExponentialWeatherer* & weathering of bedrock on hillslopes & Python \\
TransportLengthHillslopeDiffuser* & hillslope diffusion & Python \\
Vegetation* & productivity, biomass, and leaf area index & Python \\
SoilMoisture* & root zone soil moisture & Python \\
DepthDependentDiffuser* & depth- and slope-dependent linear diffusion & Python \\
FaSTMECH & river flow and morphodynamics solver & Fortran \\
PRMSStreamflow & river channel flow (Muskingum routing) & Fortran \\
PRMSGroundwater & subsurface water flow & Fortran \\
PRMSSoil & soil zone flow & Fortran \\
PRMSSurface & surface water flow & Fortran \\
\hline
\end{tabular}

* Landlab component

to note when reading through this list, apart from the diversity of models, is that models span a range of granularity (i.e., the size of a model's scope). Granularity ranges from a single equation (for example, from hydrology, the Richards equation or Green-Ampt method of model infiltration) to a collection of coupled process models (or even a complete modeling framework, e.g., CHILD, Tucker et al., 2001, or Sedflux3D, Hutton and Syvitski, 2008). However, we find that the most useful model size is one between these two extremes, which simulates a single physical process (for example the compaction of sediment under an overlying load, or the transport of sediment by way of hypopycnal sediment plumes). Models of this size are flexible in the number of other models they can couple with but not so small that they do not justify the extra overhead of creating a separate component.

We have included with the pymt a collection of tools that a modeler can use to connect a disparate set of models. For example, models will not necessarily operate on the same spatial grid and thus may have different spatial resolutions or even different grid types (e.g., raster versus unstructured mesh). To overcome this problem, we use the Earth System Modeling Framework (ESMF) grid mapper, which uses interpolation to translate variables between grids. Using this grid mapper, a modeler can write a script that gets grid values from one model, and pymt will automatically map them 
onto the grid of another (Fig. 7). For more on these grid mapping capabilities, see ESMF Joint Specification Team, 2021.

Another common issue when exchanging data between models in a coupled is system is unit mismatches. To address this issue, the pymt contains a Python wrapped version of the udunits unit conversion library. When connecting components within pymt, the user specifies the units for quantities that components will either use or provide. As with grid mapping, the pymt decorates the standard BMI with additional functionality, thus leaving these common tasks to the framework rather than to the developer of each model. The two quantity converters (grid mapping and unit conversion) target the BMI get_value methods, i.e., the differences in quantities defined on a spatial grid. However, two models can also differ temporally.

Depending on a model's time resolution, the algorithm it uses to solve a set of equations, or the timescale being simulated, models may not advance forward time at compatible intervals. However, when coupling models, we require the exchange of quantities to be made when models are synchronized in time. While the BMI update_until method could be used for this, we recognize (for some of the reasons listed above) that not all models can realistically implement this method. For such cases we have added time interpolators to the pymt by way of a modified update_until method that estimates values at intermediate time steps. The pymt accomplishes this by temporarily saving quantities at previous time steps and then interpolating between time steps. Consider, for example, a user who wants to couple two models: the first advances in time at $\Delta t_{1}$ and the second at a larger time step of $\Delta t_{2}$. Both models sit at time $t_{0}$ but the first wants to get a quantity, $x(t)$, from the second at $t=t_{0}+\Delta t_{1}$. To do so, pymt advances the second model by its time step to $t=t_{0}+\Delta t_{2}$ and returns an interpolated value of $x\left(t_{0}+\Delta t_{1}\right)$. pymt does this behind the scenes within the second model's update_until method.

Figure 7 shows the results of a coupling experiment that demonstrates some of pymt's capabilities. Here we have coupled the landscape evolution model CHILD with the seascape evolution model sedflux3D. The landscape is uplifted and eroded by CHILD, including fluvial transport of sediment to the coast. At the coast, sedflux3D takes over and transports sediment to the seafloor through surface sediment plumes and builds up a delta over time, which becomes part of the subaerial landscape (and thus part of the domain of CHILD). For every time step, CHILD passes river fluxes to sedflux3D which, in turn, passes updated landscape elevations back to CHILD. Apart from the difference in domains (land versus sea), the two models also differ in their computational grids: CHILD uses an unstructured mesh while sedflux3D uses a uniform rectilinear grid. The pymt manages the time stepping, variable exchange, and the mapping of variables between the two grids.

In addition to providing a set of coupling tools, pymt provides an interactive environment to couple and run models.
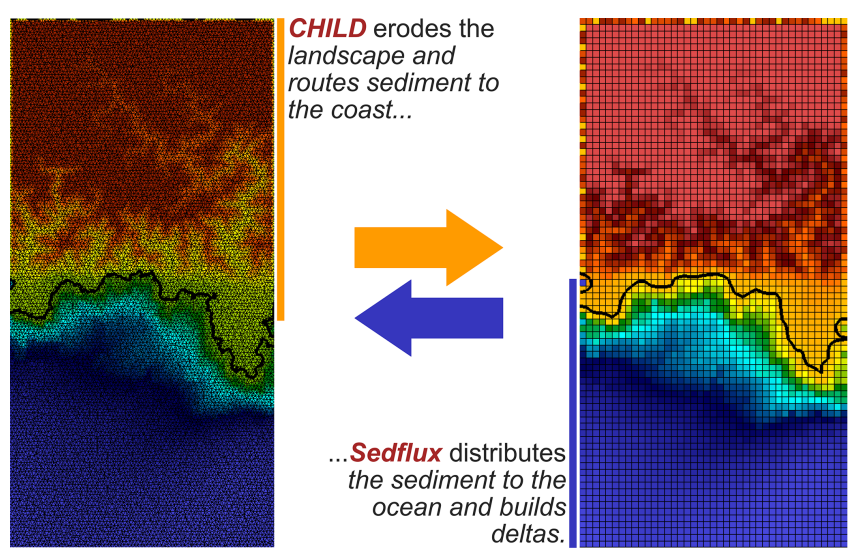

Figure 7. Results of a coupling experiment using the Python Modeling Toolkit (pymt). The CHILD model (C++; unstructured mesh) erodes an uplifting landscape and transports sediment to the coast. Sedflux (C; structured rectilinear grid) sends sediment from the coast to the ocean as surface plumes where it then settles onto the seafloor. As sediment accumulates on the seafloor, deltas begin to form and this new landscape is sent back to CHILD, completing the two-way coupling between these two pymt components.

Although the two models in our previous example were written in C (sedflux3D) and C++ (CHILD), when imported as Python classes in pymt, users are able to instantiate and run the two models interactively. A user advances models one time step at a time and can then query or even change values dynamically. When run in their native languages, a user would set the initial conditions for a model simulation and then let the model run to completion before examining output. A user would never be able to dynamically change values as it advanced. The functionality that pymt provides allows a user to experiment interactively, examining state variables as the model evolves, and dynamically changing model state variables as it advances - all within a Python environment with its large collection of visualization and analysis packages.

\subsection{Data components}

Researchers rarely use numerical models in isolation. Working with models nearly always includes working with datasets too: the data that go into a model as input, the output data that a model produces, and the data to which a model's output is compared. Productivity suffers when these datasets are cumbersome to access and use. Just as model interface standards like BMI make it easier to work with numerical models, standardized methods for data access and retrieval can ease the burden of working with data. To that end, CSDMS has developed a programmatic approach that uses the BMI for data retrieval and access. Functions such as initialize() retrieve and open a dataset, and get_value () fetches particular data items or subsets. A program that uses the BMI to access items from a particular 
dataset is known as a data component. Using the same interface for model and data operation makes it easier to swap models and datasets; for example, one might compare use of model-calculated versus measured wave heights in a simulation of coastal sediment transport. Because CSDMS data components are written in Python, they can take advantage of data-management packages like pandas and xarray.

The data components are designed to provide a consistent way to access various types of datasets (e.g., time series, raster grid, and multidimensional space-time data) and subsets of them without needing to know the original file formats. Each data component effectively "wraps" a dataset with a BMI (with the exception of certain BMI functions, such as set_value, which do not apply to datasets). Data components can easily interact with BMI-enabled numerical models in the pymt modeling framework or other similar frameworks.

One example is the National Water Model (NWM) data component. This data component can access and subset the forecasted streamflow time series generated by the NWM hydrologic modeling framework. Figure 8 shows an example of how the NWM data component can be used to get the streamflow data at a river channel for a flooding event. Figure 9 shows the corresponding time series plot. This data component includes a set of standard control and query functions (e.g., initialize (), update ()). These standard methods make the dataset easier to couple with BMI-enabled numerical models without needing to know the time series file format.

\subsection{Creating new models: Landlab}

Landlab is a Python-language library designed to support the creation, combination, and reuse of 2-D models (Hobley et al., 2017; Barnhart et al., 2020a). For the moment, let us presume that a model developer has identified input and output parameters, model state variables, and the governing equations and/or model rules. We might then synthesize the tasks of building the model (Sect. 4.6) into two types: (a) creating required data structures and (b) implementing a numerical solution to the governing equations that act on those data structures. For example, most models need to represent the computational domain, including information across the domain, and adjacency information describing how the different parts of the domain are connected to one another. This division is simplistic and neglects many intricacies, yet it captures the fundamental activities of model building.

Landlab provides reusable software infrastructure that addresses the most common needs for our two model-building tasks. For grid-based data structures, Landlab provides a grid object to represent the computational domain and store fields of state variables (Fig. 10). Landlab provides several twodimensional grid types, which all share the same underlying graph-based data structures. Current grid types include regular raster, network, regular hexagon, and unstructured
(Delaunay-Voronoi). For all grid types, the adjacency information and access to fields follows the same interface - making it easier for a model to work on multiple grid types.

To address the second model-building task, Landlab provides two capabilities. First is a set of numerical utilities that support common needs. These include, for example, the ability to calculate differences, gradients, fluxes, and divergences of values stored at fields. Second is a library of components (Fig. 11). Each Landlab component simulates a single process, such as routing of shallow water flow across a terrain surface (Adams et al., 2017), calculating groundwater flow (Litwin et al., 2020), modeling sediment movement in a river network (Pfeiffer et al., 2020), or simulating biological evolution across a landscape (Lyons et al., 2020). Components are implemented as Python classes, and are derived from a common base class that defines common attributes, and enforces a minimum set of metadata for each component. If a researcher wishes to write the code for a numerical model, and the desired elements of that model have already been implemented as Landlab components, the model can be programmed efficiently by instantiating each component, and then executing the run_one_step method for each component within a loop (Fig. 11).

The component base class was designed to expose a Basic Model Interface (BMI; Sect. 6.1), which allows a Landlab component to be used as a BMI-enabled component. Although we do not expect most Landlab users to directly use this alternate interface, the component's BMI acts as a bridge that allows it to be incorporated into other BMI-friendly frameworks and tools (e.g., pymt, dakotathon).

The Python Modeling Toolkit (pymt; Sect. 6.3) is a modelcoupling framework that provides tools for using and coupling BMI-enabled components, written in a range on programming languages, which may not have been written with the intent of operating within a coupling framework. Operating as a BMI component, Landlab components act as isolated elements that no longer share a common grid and data; when used in this mode, Landlab components require an input file that describes the grid, parameter values, and initialization setup. This is by design and required by the BMI so that a user interacts with the component as with any other BMI component without being aware of the inner workings of a Landlab component.

Despite the name, Landlab is not restricted to terrestrial processes. Its component collection includes, for example, components for coastal and marine processes such as tidal circulation and marine sedimentation. Its design is amenable to a wide variety of $2 \mathrm{D}$ grid-based numerical models and cellular automata applications. Landlab can be used, for example, to construct integrated source-to-sink models that treat the full geologic cycle, tracking sediment from its creation on land to its deposition in marine basins (Fig. 12).

The design of Landlab supports a variety of usage styles. Interested users and/or developers may use Landlab to create models as components, or as scripts that combine compo- 


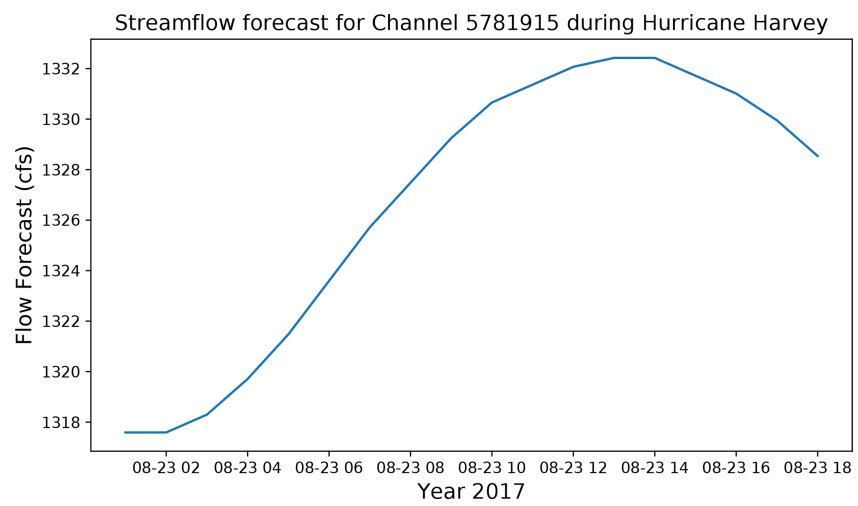

Figure 9. Time series plot for the accessed NWM streamflow dataset.

performant, parallel-capable algorithms developed by Barnes (2016). In addition, bottleneck code elements in Landlab components and core routines are often rewritten in Cython, which is a Python-language extension that provides explicit type declarations and translates to $\mathrm{C}$ code that is compiled into importable object modules. In general, Landlab's modular design facilitates performance benchmarking by enabling one to compare performance between components that use different algorithms or codes to execute the same task.

\subsubsection{HyLands: an example of a component-based integrated model}

The modular design of Landlab enables the development of numerical tools in an efficient manner. An example of a recently developed Landlab-built model is HyLands: a landscape evolution model that simulates mass wasting and sediment redistribution on hillslopes. The model was originally written in a closed-source language (Campforts et al., 2020); translating the original code into Landlab converts the original product into a fully open-source tool for the broader community and provides a new process component to simulate landsliding. The grid engine and other tools available within the Landlab library enabled efficient implementation and provide capabilities for coupling with other existing Landlab components. An example is the Stream Power with Alluvium Conservation and Entrainment (SPACE) component, which has been developed to simulate fluvial sediment transport and incision (Shobe et al., 2017) and is showcased here as an example of model coupling with HyLands.

The integration capabilities of Landlab, where new and existing components can be combined in a straightforward way, opens up new possibilities for applied environmental engineering and fundamental scientific research. For HyLands in particular, the coupling of a deep-seated landslide algorithm with a sediment routing system will (i) help on a more applied level to explore the impact of future changes in storm frequency on landslide occurrence and sediment dynamics (Fan et al., 2019) and (ii) on a more fundamental level to fa- cilitate the investigation of the interaction between landslides and sediment dynamics over geological timescales. The latter is illustrated in Fig. 13, where we use the Landlab software to simulate the impact of uplifting terrain on the formation of alluvial fans. Simulations are executed with and without landslide activity (Fig. 13a versus 13b). Resulting magnitude-frequency and area-volume relationships for the simulated landslides are shown in Fig. 14. The evolution of the alluvial fans is further visualized in the movies listed in Table 4. For details regarding the algorithms and physics supporting the HyLands component, see Campforts et al. (2020).

\subsection{Standard Names}

Ensuring interoperability when coupling models or selecting datasets as inputs to models requires accurate alignment of scientific variables. Scientific variables are complex concepts composed of multiple facets - a phenomenon or object of observation, the corresponding physical quantity being measured, spatiotemporal context for the phenomenon, spatiotemporal reference for the measured quantity, mathematical operations applied to transform the physical quantity, etc. Because of this, and because terminology varies across disciplines, the semantic mediation task - determining whether two variables represent compatible concepts - can be quite involved. In CSDMS, BMI works in tandem with the CSDMS Standard Names (CSN) (Peckham et al., 2013) to ensure proper alignment between resources. The Standard Names were developed to standardize and unify the representation of scientific variables within CSDMS.

A CSDMS Standard Name contains two parts: an object part and a quantity part, with adjectives and modifiers (as prefixes) being used to help avoid ambiguity and identify a specific object and a specific, associated quantity. The quantity part may include one or more operation prefixes that create a new quantity from an existing quantity. An example related to surface-water hydrology is the runoff rate, for which the Standard Name is as follows.

land_surface_water_runoff_volume_flux

The double-underscore separates the object (surface water on land) from the quantity (the volume flux of runoff). The word "flux" implies a quantity per time per surface area, and thus the implied dimensions are length per time.

As with all standard naming approaches, the Standard Names are limited in the amount of information they can represent because their data model and definitions are not explicitly represented. The Scientific Variables Ontology (SVO) (Stoica and Peckham, 2018, 2019b, a; Stoica, 2020; SVO, 2020), a blueprint for representing scientific variables utilizing a compact set of domain-independent categories, relationships, and modular design patterns, was developed to address these issues. In computer science, an ontology is a system that attempts to capture and organize knowledge in 


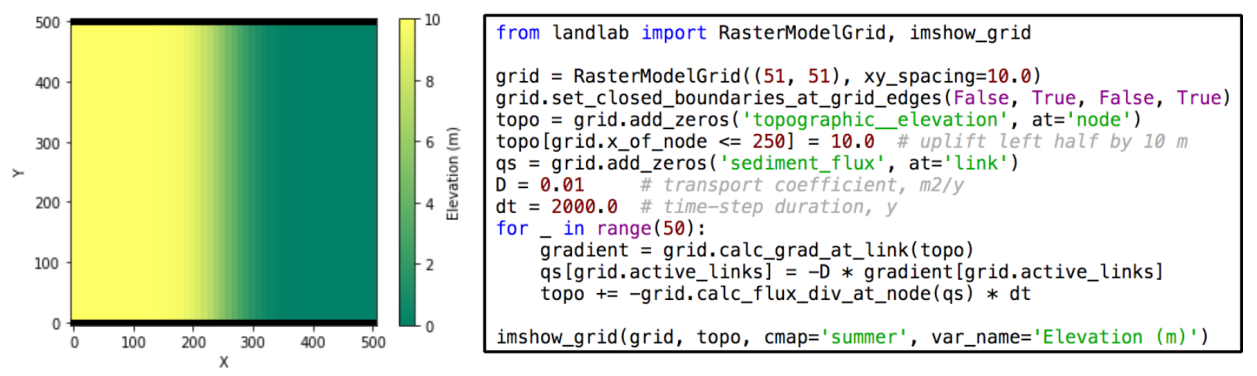

Figure 10. Example of a simple finite-volume numerical model of hillslope evolution, written in Python using the Landlab library. The model uses a diffusion equation to represent an evolving hillslope. The concise source code at right illustrates the use of a Landlab grid object together with fields and built-in functions for numerical gradient and divergence functions on these fields.

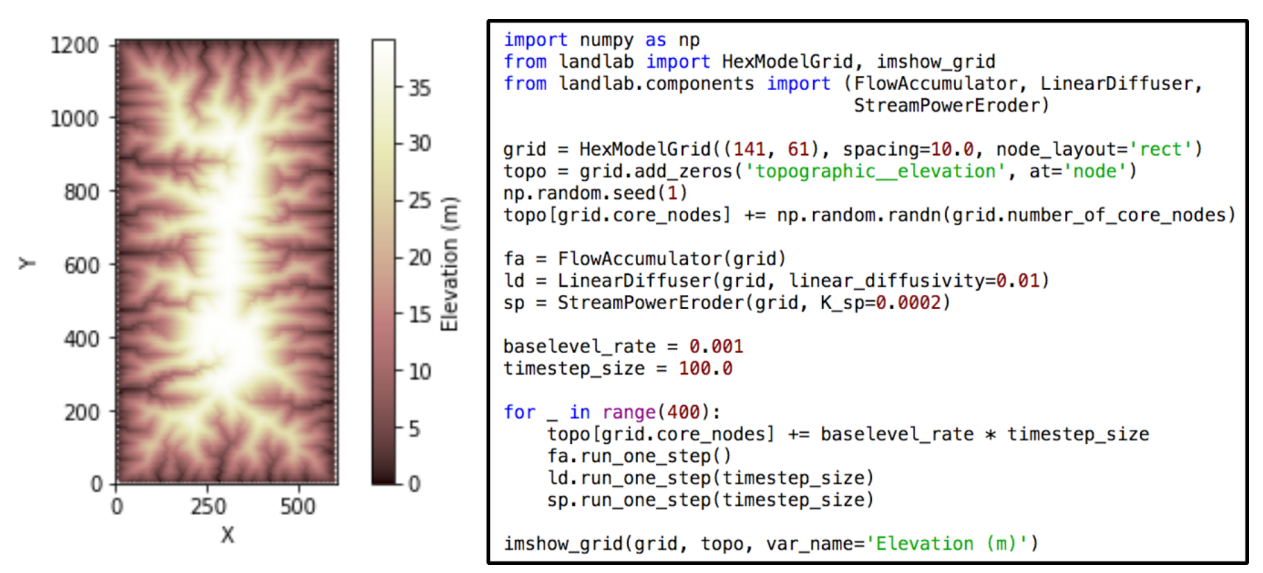

Figure 11. Example of a simple landscape evolution model written using the Landlab programming library. Model code at right illustrates the use of three components to create the model.

a particular domain (in machine-readable form) as understood by experts in that domain or subject area. In SVO, the CSN are represented with an explicit, formal model in machine-readable form using Semantic Web best practices (W3C Working Group, 2008). Because SVO is formalized, it can be used to enable searching, semi-automated generation of new variable representations, and inexact but sufficient variable alignments through logical reasoning.

\section{Community engagement}

One of CSDMS' major activities has been the creation of a thriving community around Earth surface dynamics modeling (Overeem et al., 2013). As of 2020, over 2000 members, representing 552 institutions (144 US academic) and 71 countries, had joined the community. CSDMS is, by design, a broad and deep coalition of members from disciplines reflected by five Working Groups and seven Focus Research Groups (Fig. 15). From its inception, CSDMS has encouraged trans-disciplinarity by providing opportunities such as annual meetings, workshops, hackathons, and training events for domain scientists to interact with colleagues from other Earth and social science disciplines. These connections are essential for knowledge exchange among community efforts and allow for wider penetration of new technology and ideas. Cross-pollination of ideas from these events and other community-member interactions have led to a variety of independently funded research projects. CSDMS has played a key role in shifting the paradigm to open code-sharing in Earth surface processes by facilitating resource-sharing through model, data, and education repositories on the CSDMS web portal. CSDMS also offers a variety of services to community processes and the geoscience subdiscipline of interest. Along with their disciplinary expertise, researchers who work with computational models also need a strong foundation in programming, advanced computing, and data analytics (Atkins et al., 2011).

Traditional Earth science education does not usually equip students with skills to use modern cyber-infrastructure and computing resources efficiently or to become model developers (Campbell et al., 2013). The Earth surface processes community critically needs a platform to teach modern programming practices and high-performance computing methods to develop innovative models that can be used to understand and predict how the Earth's surface responds to environmental change and human influence. The practice of 
Table 4. Simulation movies created with Landlab-HyLands.

\begin{tabular}{lll}
\hline Scenario & Description & Link \\
\hline No landslides & topography & https://youtu.be/c5d7T8eehxw \\
& $\begin{array}{l}\text { location of longest river } \\
\text { river profile }\end{array}$ & $\begin{array}{l}\text { https://youtu.be/GqokukWi9cs } \\
\text { https://youtu.be/A_JZ9POfJ54 } \\
\text { https://youtu.be/t0_tel5fhbM }\end{array}$ \\
\hline Landslides & topography & https://youtu.be/1K_ceKYt9Nw \\
& location of longest river & https://youtu.be/YkmbUTN7zlI \\
& river profile & https://youtu.be/jyWgKTcMe74 \\
& sediment thickness & https://youtu.be/rwEBqGtHZs0 \\
& landslide erosion and deposition & https://youtu.be/_xoSm7p4ZxI \\
\hline
\end{tabular}

Last access date for all URLs: 11 February 2022

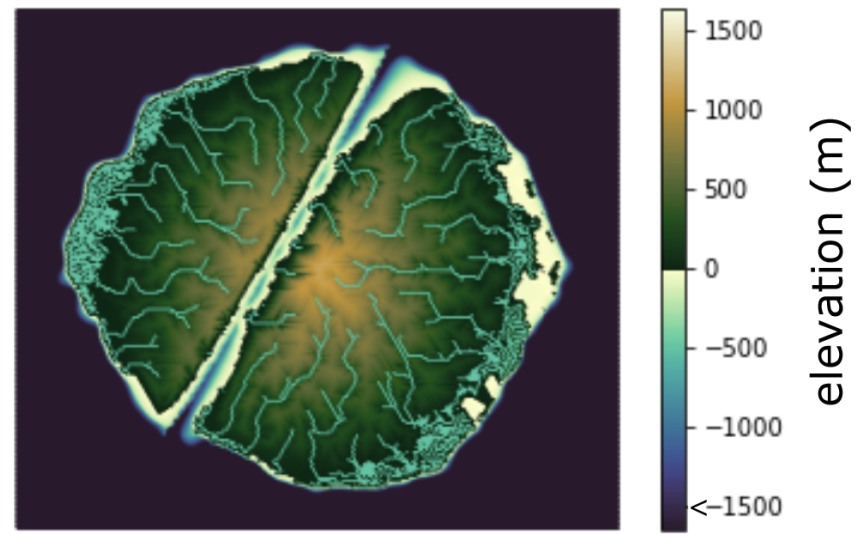

Figure 12. Snapshot of prototype integrated numerical model of landscape and sedimentary basin evolution. Domain size is 250 by $250 \mathrm{~km}$. Simulation shows a hypothetical micro-continent with an active NNE-oriented extensional fault. Sea level varies stochastically; this particular snapshot captures a period of rising sea level after a brief low stand. Model was constructed using Landlab components for flow routing (FlowAccumulator, FlowDirectorSteepest, LakeMapperBarnes), fluvial processes (ErosionDeposition), marine sediment transport (SimpleSubmarineDiffuser), lithosphere flexure in response to loading and unloading (Flexure), and extensional faulting (ListricKinematicExtender). Color map designed by Thyng et al. (2016).

modeling lies at the core of predictive Earth surface sciences, and educators should engage students in building, testing, and applying models (Hestenes, 1996; Manduca et al., 2008), but we found from a review of course catalogs that in practice the undergraduate curricula of more traditional discipline-focused departments do not include this component (Campbell et al., 2013). This issue is not entirely unique to Earth surface sciences. The geosciences today are intensively quantitative, and there is an urgent need for a workforce with strong STEM skills (Singer et al., 2012). The United States' National Science Foundation (NSF) recognizes as one of its "10 Big Ideas" that pathways are needed for educators to create a 21st-century workforce capable of effectively dealing with data (King and South, 2017). Moreover, an agile STEM workforce is considered a national priority (Atkins et al., 2011). Realizing this, CSDMS provides hands-on training opportunities during meetings. Some efforts are meant to build foundation - for example, via short courses that equip graduate students with skills in best programming practices. Other outreach efforts consist of short clinics, targeted to give potential users of cyber-infrastructure an active feel for certain models or computational techniques or to provide an update to experts on new developments. More extensive separately organized hackathons bring together small science teams to work on solutions for more specific outstanding research problems. In 2020, CSDMS inaugurated an immersive Earth Surface Processes Summer Institute for students and early career scientists, focused on capacity building for Earth surface processes modeling.

\section{Discussion and conclusions}

In May 2020, the US National Science Foundation released a special report, prepared by the National Academy, on research opportunities in the Earth sciences (NRC, 2020). The report highlighted three unique types of research infrastructure: instrumentation, human infrastructure, and cyber-infrastructure. The report's recognition of cyberinfrastructure as a distinct form of research infrastructure is one indication of the critical role that computing now plays in the Earth and environmental sciences. Environmental modeling, and the software and culture-of-practice that support it, constitutes a key part of that cyber-infrastructure. Research software is infrastructure and is deserving of the same care and attention as a laboratory or field station. This is also true of the professional research software engineers who devote their expertise to helping the community do computational work more efficiently, effectively, and sustainably.

The research enterprise benefits when modeling software and tools are shared, coordinated, and interoperable, such 

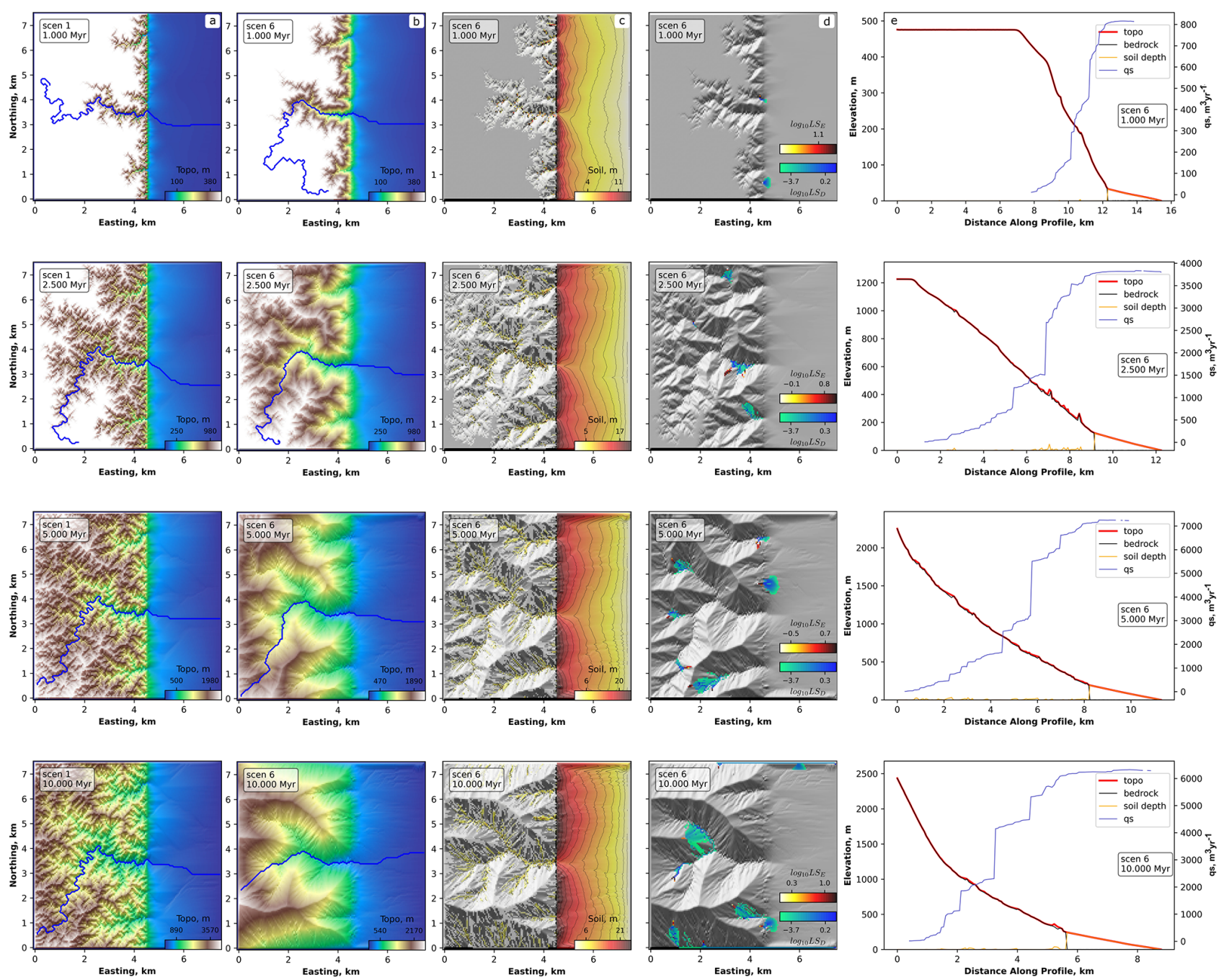

Figure 13. Illustration of HyLands model component. (a) Time slices showing evolution of the landscape to steady state without landsliding. The blue lines represent the plan-view locations of rivers plotted in the right-hand column. Column (b) is the same as column (a) but with landsliding. (c) Sediment accumulation and the formation of alluvial fans (with landsliding). (d) Landslide activity during the depicted time step. Red colors represent the logarithm of the landslide erosion depth; blue colors represent deposition. Column (e) shows the topographic and bedrock elevation (red and black line, respectively) and the sediment thickness (orange line). The sediment flux is plotted against the right-hand $y$ axis (blue line). Note that during landsliding both pure landslide dams (red bumps on the profile) and irregularities in the bedrock profile (grey bumps) arise. The latter originate from the river being redirected after landsliding, forming epigenetic gorges.

that the six model operation tasks listed in Fig. 2 can be done efficiently and effectively. For the Earth surface sciences, the CSDMS Model Repository provides a community platform for finding and sharing model codes and related tools. In addition to acting as a valuable community resource, the Repository provides a solution to the growing mandate from journals and funding agencies to make research software openly available. The provision of standardized metadata and bibliographic information helps those who are looking for models to compare and evaluate the alternatives.

Simply providing source code and metadata is not enough, however. In order for Earth and environmental models to function as community resources, they must be usable, and one of the key dimensions of usability is interoperability. The BMI standard promotes interoperability by reducing the learning curve for executing and querying models, and by greatly simplifying the process of linking (one way) or coupling (two way) models. A model program equipped with a BMI becomes an interoperable, standardized component: an element of an integrated system, rather than an idiosyncratic standalone product. One of the key abilities offered by a BMI-enabled model is run-time control, query, and modification. Because BMI supports step-wise execution, a user can effectively pause a model mid-run to inspect its state variables and modify parameters or data. This capability allows iterative, loop-based coupling of models using simple scripts. 


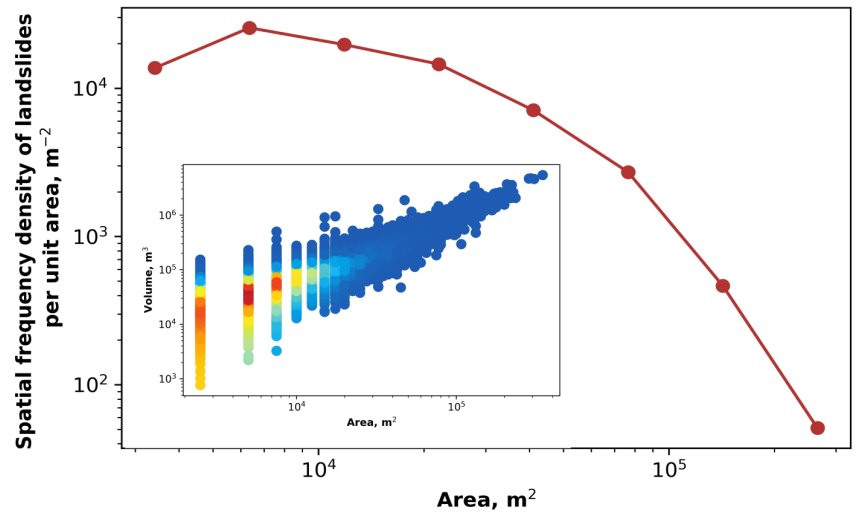

Figure 14. Magnitude-frequency relationship of the landslides simulated with Landlab-HyLands (red dots) and illustrated in Fig. 13. The inset shows a scatter density plot showing the simulated areavolume relationship.
Working Group Membership

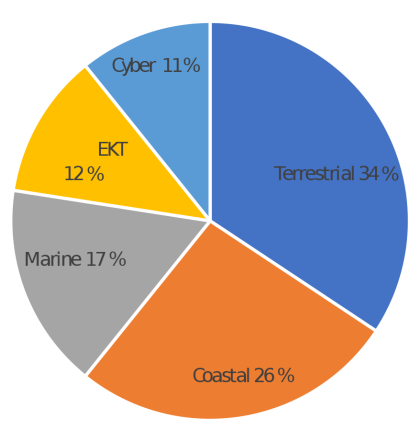

Focus Research Group Membership

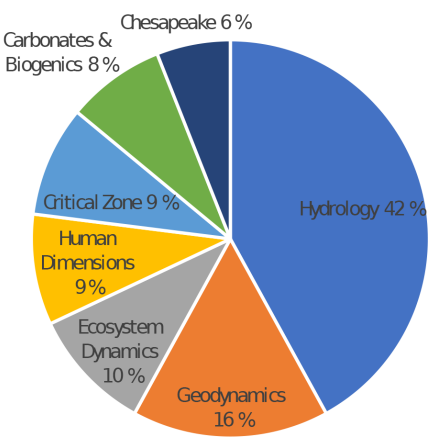

Figure 15. CSDMS Working Groups and Focus Research Groups (EKT stands for Education and Knowledge Transfer).

The ability to query and modify values also enables tighter coupling. For example, if component models are treated as representing individual terms in a governing equation, a coupling script can use BMI functions to query each component's derivatives, construct a matrix, solve it, and then pass the updated state variables back to the individual components.

One advantage of BMI is that it is language agnostic and can in principle be implemented in nearly any programming language. It can, for example, accommodate legacy codes written in Fortran. The disadvantage of language flexibility is that BMI addresses the least common denominator, and therefore does not take advantage of the more advanced features available in some languages, such as object-oriented capabilities. To some extent this disadvantage can be addressed by building more specialized, language-specific interfaces in parallel with a BMI. For example, Landlab components, which are implemented as classes, use a lightweight, Python-specific interface that takes advantage of that language's object-oriented capabilities, advanced data types, and parameter-passing syntax. At the same time, Landlab also includes functionality to translate any of its components into a standard BMI component so that they can be integrated with components written in other languages.

The flexibility that BMI offers has led to its adoption in a variety of different applications, including US Geological Survey rainfall-runoff models (Markstrom et al., 2015; Regan et al., 2018, 2019), hydrodynamic modeling (including flagship models developed by Deltares and the Netherlands eScience Center, Hoch and Trigg, 2019; Hoch et al., 2019), delta and coastline evolution modeling (Ratliff et al., 2018), and modeling of methane emissions (Fox et al., 2020). One disadvantage of a standard interface like BMI is the extra upfront investment in program development. Researchers may not perceive value in adding a standard interface to a legacy code or writing it into a new code. However, for codes whose scope merits repeated reuse, this effort usually more than pays for itself. Code written to a standard like BMI tends to be more modular and therefore easier to maintain. Existing templates for common languages in the Earth and environmental sciences make the process of providing a BMI to a new program relatively painless, i.e., just a matter of filling in a set of predefined function names and signatures (Hutton et al., 2020a). Adding a BMI to an existing legacy model can be a bit more involved, depending on how the program code is structured, because it often requires some degree of refactoring. Even in that case, we find that adding a BMI to a legacy model often makes that code more understandable and adaptable.

The variety of different programming languages used in the Earth and environmental sciences community presents a barrier to interoperability. The majority of models and tools in the CSDMS Repository are written in C, C++, Fortran, Python, and MATLAB (Fig. 4). Other languages used in CSDMS constituent communities include R (especially in ecosystem dynamics) and NetLogo's java-based scripting language (for agent-based modeling). Julia, a relatively new high-level language oriented toward numerical computing, also seems to be growing in popularity in the science community. Crossing the language barrier requires languagebridging tools. Translating the existing wealth of legacy code into a single, common language would be impractical, even if the community could agree on which language to use. A more effective solution is to librarize models and tools (Brown et al., 2014) as components that can be accessed and executed through a high-level scripting language. In CSDMS' case, the Babelizer tool provides this capability for codes written in $\mathrm{C}, \mathrm{C}++$, and Fortran by using Python as the bridging language.

Librarization can also be applied to tools that access datasets. The CSDMS Workbench accomplishes this with data components that provide function-call access to various datasets. Using the BMI syntax for data access removes the need to worry about data formats and makes it easier to swap between datasets and models (for example, data versus 
model of ocean wave properties) as components in a linked system. In this case, the BMI does not replace the more sophisticated data-access capabilities of a language-specific library like xarray, but it has the advantage of providing a consistent interface across multiple languages.

For building and modifying numerical models, the CSDMS Workbench provides Landlab as a Python-specific solution for 2D, grid-based applications. Experience with Landlab since its introduction has shown that a library of model "building blocks" can greatly reduce barriers on the software side of model creation. One indicator of the success of this approach is the growing number of Landlab-built models created by doctoral students as part of a larger body of dissertation research (e.g., Adams et al., 2017; Gray et al., 2017; Shobe et al., 2017; Lai and Anders, 2018; Langston and Tucker, 2018; Schmid et al., 2018; Strauch et al., 2018; Glade et al., 2019; Reitman et al., 2019; Carriere et al., 2020; Litwin et al., 2020). The ability to assemble models out of reusable "process components" allows for rapid construction of complete, multi-element models. One example of the value of rapid model assembly is a recent comparative testing and calibration study of long-term landform evolution models (Barnhart et al., 2020b, c). The study authors used Landlab to develop a Python package for multi-model analysis of drainage basin evolution (Barnhart et al., 2019). The package allowed for the exploration and testing of more than 30 mathematically distinct models as alternative hypotheses - a feat that would not have been possible with a traditional monolithic modeling code. This example illustrates how flexible, component-based modeling software promotes hypothesis testing.

Experience with BMI, pymt, and Landlab highlights the critical importance of documentation, consistent with the findings of Lawrence et al. (2015). Tutorial examples in particular provide a starting point that users can build on. Embedding tutorials in Jupyter Notebooks provides an effective way to combine descriptive text, program code, plots, and formatted mathematics. For reference-level documentation, document generator tools like Sphinx and doxygen translate internal documentation (comment blocks inside source code) into nicely formatted, web-accessible reference material.

One limitation in the current pantheon of community Earth surface dynamics software is the unevenness of software testing. In the context of numerical models, Clune and Rood (2011) define two very different forms of testing: confirming consistency between a model and the natural or engineered system it is meant to represent (which they term validation) and verifying that the code reproduces an independently known or calculated solution to its algorithms. The first is an intrinsic part of the scientific method, and often the motivation for developing models in the first place. The second verification testing - is a quality-control practice that guards against software bugs that could otherwise misdirect the science. As noted in Sect. 2, formal verification testing in research software seems to be under-used in research software.
In the CSDMS Model Repository, relatively few communitycontributed standalone codes come equipped with formal tests as part of their software package. Yet our own experience has proven the value of weaving unit tests and other types of test into a software package. The Landlab Toolkit, for example, includes unit tests that collectively exercise about $85 \%$ of the entire source code. Requiring these tests to pass before merging changes has proven to be a powerful (though not foolproof) method for screening out bugs and unintended side effects. Tutorial-style documentation can also provide an opportunity for testing: we have found that simply checking for run-time errors in Jupyter notebook tutorials provides an additional level of screening that encompasses more complex use cases than most unit tests cover. We have also found that test-driven development can be an effective and efficient way to write modeling software, with the added benefit that tests become incorporated from the start as part of the development process (Nanthaamornphong and Carver, 2017, 2018). Increasing the use of techniques like test-driven development and unit testing among the geoscience community will require a combination of educational opportunities and guided community development.

A successful community cyber-infrastructure for numerical modeling requires more than just technology. It also takes community building and coordination. In the case of CSDMS, the community centers around common interest in a broader theme (Earth surface processes) and a common approach (modeling). Activities such as meetings, workshops, hackathons, and webinars can help draw attention to new tools and methods, provide education in their use, and contribute to building a culture of resource sharing.

One of the biggest challenges to a fully functional community software ecosystem in Earth and environmental modeling is a lack of formal training in computational skills. Most geoscientists are self-taught programmers and generally unaware of practices and tools that would make their work more efficient and sustainable. CSDMS and other community facilities have had some success in addressing this need with workshops, webinars, and summer schools, but there remains a need to scale up these efforts. Geoscience researchers should not need the equivalent of a computer science degree to perform computational research, yet in our experience there is a basic set of skills that can make a big difference but that relatively few geoscientists possess. The taxonomy of model-related tasks in Fig. 2 could potentially serve as a guidepost for defining learning goals. For example, in practice most of the task levels in Fig. 2 require the ability to operate a command shell. Most of the levels also require the ability to manipulate input and output data, and the higher levels require familiarity both with programming and with numerical methods. Potential approaches to instructional delivery range from regular university-based geoscience-oriented courses, to focused community-led summer courses, to fully online self-paced courses. Questions of credit and funding 
inevitably arise, as does the issue of how to squeeze more material into already-packed curricula.

Another challenge revolves around incentives. The community as a whole clearly benefits from a FAIR and sustainable research software ecosystem. As noted above, the advent of software journals and peer-reviewed repositories (such as CoMSES Net and pyOpenSci) provides one mechanism to encourage the creation of lasting digital products. The reproducibility movement provides another useful push and has led journals and funding agencies to raise their standards for sharing and accessibility of software and other digital products. To take advantage of this momentum, hiring and promotion committees at universities and research organizations need to acknowledge the value of contributions to high-quality research software. Professional societies can contribute by offering awards that recognize contributions to cyber-infrastructure.

The third major challenge is support. Our experience with CSDMS demonstrates that a modest investment in community-oriented computing can have a substantial positive impact on research productivity. By investing in stable community repositories, interoperability standards, and software libraries and frameworks, a funding agency can increase the impact of its portfolio by incentivizing a shared, reusable, and ever-improving community infrastructure of models, tools, and expertise. A key to making this approach scalable, in addition to incentives, is to provide sufficient documentation and consulting support to enable community members to create research cybertools that are findable, accessible, interoperable, and reusable. We have found from our own experience that consulting support is an especially important piece. Projects that include a professional research software engineer in their team - even if it is just at the level of general design advice, informal education, or to help overcoming technical obstacles - tend to be much more likely to produce robust, flexible, sustainable software as a lasting broader impact of a project.

Computational modeling in the Earth and environmental sciences has come a long way in the first 2 decades of the 21 st century. The possibilities of a coordinated, community-wide cyber-ecosystem are starting to emerge. Fully achieving this vision will require a combination of education, incentives, and support. Universities, research agencies, and individual researchers all have a role to play.

Code availability. The current versions of the various elements in the CSDMS Workbench software suite are available under the MIT license. As of this writing, Landlab code, documentation, and tutorials are available in a Git version-control repository on the GitHub hosting site at https://github.com/landlab/landlab (last access: 11 February 2022). Documentation can be accessed at https:// landlab.github.io (last access: 11 February 2022). The Landlab version discussed here is 2.0 ("Mrs. Weasley"), available via Zenodo at https://doi.org/10.5281/zenodo.3776837 (Hutton et al., 2020b).
Current versions of software, technical specifications, documentation, and other resources for other Workbench elements (BMI, babelizer, pymt, model, and data components) are managed on GitHub under the CSDMS organization (https://github.com/csdms, last access: 11 February 2022). Online documentation for BMI, pymt, and babelizer is presently hosted on the Read the Docs platform (for example, https://bmi.readthedocs.io, (last access: 11 February 2022). The BMI version presented in this paper is 2.0, available via JOSS and Zenodo at https://doi.org/10.21105/joss.02317 (Hutton et al., 2020a). Babelizer version 0.3 .8 can be found at https://doi.org/10.5281/zenodo.4985181 (Hutton and Piper, 2021). Version 1.3 .1 of the Python Modeling Toolkit (pymt) can be accessed at https://doi.org/10.5281/zenodo.4985222 (Hutton et al., 2021). The simulation shown in Fig. 12 is contained and described in two Jupyter Notebooks available at https://doi.org/10.5281/zenodo.6049847 (Tucker, 2022).

Data availability. Data on CSDMS membership, as shown in Fig. 15, are openly available at https://csdms.colorado.edu/wiki/ CSDMS_members_by_numbers (Kettner, 2022).

Author contributions. CSDMS is the outcome of a communitywide effort, with contributions from numerous community members to governance, workshops, software, educational resources, and ideas. In terms of this particular manuscript, primary author contributions by section were as follows: Sects. 1-4 were contributed by GET; Sect. 5 was contributed by AJK; Sect. 6 was contributed by MDP, EWHH, TG, BC, KRB, GET, and SDP; Sect. 7 was contributed by IO and LM; and Sect. 8 was contributed by GET. JS founded CSDMS and led it for 10 years. All authors contributed to editing the manuscript.

Competing interests. The contact author has declared that neither they nor their co-authors have any competing interests.

Disclaimer. Publisher's note: Copernicus Publications remains neutral with regard to jurisdictional claims in published maps and institutional affiliations.

Acknowledgements. We are grateful for the feedback and helpful suggestions from two anonymous reviewers and for the work of the editorial team. The Community Surface Dynamics Modeling System (CSDMS) is supported by the US National Science Foundation (NSF) (1831623). Initial development of Landlab was supported by the NSF SI2 program (1450409). Additional sources of support include EarthCube (2026951), NSF OPP (1503559), NSF-CISE (1924259, 2104102), and an NSF postdoctoral fellowship (1725774 to Katherine R. Barnhart). The authors gratefully acknowledge the contributions of numerous CSDMS members, whose service on committees, sharing of codes, teaching of clinics, and other efforts have created a vibrant community of practice. 
Financial support. This research has been supported by the National Science Foundation (grant nos. 2104102, 2026951, 1924259, 1831623, 1725774, 1503559, and 1450409).

Review statement. This paper was edited by Andrew Wickert and reviewed by two anonymous referees.

\section{References}

Adams, J. M., Gasparini, N. M., Hobley, D. E. J., Tucker, G. E., Hutton, E. W. H., Nudurupati, S. S., and Istanbulluoglu, E.: The Landlab v1.0 OverlandFlow component: a Python tool for computing shallow-water flow across watersheds, Geosci. Model Dev., 10, 1645-1663, https://doi.org/10.5194/gmd-101645-2017, 2017.

Addor, N. and Melsen, L.: Legacy, rather than adequacy, drives the selection of hydrological models, Water Resour. Res., 55, 378390, https://doi.org/10.1029/2018WR022958, 2019.

Adorf, C. S., Ramasubramani, V., Anderson, J. A., and Glotzer, S. C.: How to professionally develop reusable scientific software - And when not to, Comput. Sci. Eng., 21, 66-79, 2018.

Ahalt, S., Band, L., Christopherson, L., Idaszak, R., Lenhardt, C., Minsker, B., Palmer, M., Shelley, M., Tiemann, M., and Zimmerman, A.: Water Science Software Institute: Agile and open source scientific software development, Comput. Sci. Eng., 16, 18-26, 2014.

AlNoamany, Y. and Borghi, J. A.: Towards computational reproducibility: researcher perspectives on the use and sharing of software, PeerJ Comput. Sci., 4, e163, https://doi.org/10.7717/peerjcs.163, 2018.

Anderson, R. S., Dietrich, W. E., Furbish, D., Hanes, D., Howard, A., Paola, C., Pelletier, J., Slingerland, R., Stallard, B., Syvitski, J., Vorosmarty, C., and Wiberg, P.: Community Surface Dynamics Modeling System Science Plan, Tech. rep., CSDMS Working Group, https://csdms.colorado.edu/wiki/CSDMS_docs (last access: 11 February 2022), 2004.

Arndt, D., Bangerth, W., Blais, B., Fehling, M., Gassmöller, R., Heister, T., Heltai, L., Köcher, U., Kronbichler, M., Maier, M., Munch, P., Pelteret, J.-P., Proell, S., Simon, K., Turcksin, B., Wells, D., and Zhang, J.: The dea I . I I Library, Version 9.3, J. Numer. Math., 29, 171-186, https://doi.org/10.1515/jnma-20210081, 2021a.

Arndt, D., Bangerth, W., Davydov, D., Heister, T., Heltai, L., Kronbichler, M., Maier, M., Pelteret, J.-P., Turcksin, B., and Wells, D.: The deal.II finite element library: Design, features, and insights, Comput. Math. Appl., 81, 407-422, https://doi.org/10.1016/j.camwa.2020.02.022, 2021b.

Atkins, D., Hey, T., and Hedstrom, M.: National Science Foundation Advisory Committee for Cyberinfrastructure Task Force on Data and Visualization Final Report, US government report, National Science Foundation, 2011.

Balay, S., Gropp, W. D., McInnes, L. C., and Smith, B. F.: Efficient Management of Parallelism in Object Oriented Numerical Software Libraries, in: Modern Software Tools in Scientific Computing, edited by: Arge, E., Bruaset, A. M., and Langtangen, H. P., Birkhäuser Press, 163-202, 1997.
Balay, S., Abhyankar, S., Adams, M. F., Brown, J., Brune, P., Buschelman, K., Dalcin, L., Eijkhout, V., Gropp, W. D., Kaushik, D., Knepley, M. G., McInnes, L. C., Rupp, K., Smith, B. F., Zampini, S., and Zhang, H.: PETSc Users Manual, Tech. Rep. ANL-95/11 - Revision 3.6, Argonne National Laboratory, http: //www.mcs.anl.gov/petsc (last access: 11 February 2022), 2015a.

Balay, S., Abhyankar, S., Adams, M. F., Brown, J., Brune, P., Buschelman, K., Dalcin, L., Eijkhout, V., Gropp, W. D., Kaushik, D., Knepley, M. G., McInnes, L. C., Rupp, K., Smith, B. F., Zampini, S., and Zhang, H.: PETSc Web page, http://www.mcs. anl.gov/petsc (last access: 11 February 2022), 2015 b.

Bangerth, W. and Heister, T.: What makes computational open source software libraries successful?, Comput. Sci. Discovery, 6, 015010, https://doi.org/10.1088/1749-4699/6/1/015010, 2013.

Barba, L. A.: The hard road to reproducibility, Science, 354, 142142, 2016.

Barnes, N.: Publish your computer code: it is good enough, Nature, 467, 753-753, 2010.

Barnes, R.: RichDEM: Terrain Analysis Software, http://github. com/r-barnes/richdem (last access: 11 February 2022), 2016.

Barnhart, K. R., Glade, R. C., Shobe, C. M., and Tucker, G. E.: Terrainbento 1.0: a Python package for multi-model analysis in long-term drainage basin evolution, Geosci. Model Dev., 12, 1267-1297, https://doi.org/10.5194/gmd-12-1267-2019, 2019.

Barnhart, K. R., Hutton, E. W. H., Tucker, G. E., Gasparini, N. M., Istanbulluoglu, E., Hobley, D. E. J., Lyons, N. J., Mouchene, M., Nudurupati, S. S., Adams, J. M., and Bandaragoda, C.: Short communication: Landlab v2.0: a software package for Earth surface dynamics, Earth Surf. Dynam., 8, 379-397, https://doi.org/10.5194/esurf-8-379-2020, 2020.

Barnhart, K. R., Tucker, G. E., Doty, S., Shobe, C. M., Glade, R. C., Rossi, M. W., and Hill, M. C.: Inverting topography for landscape evolution model process representation: Part 1, conceptualization and sensitivity analysis, J. Geophys. Res.-Earth, 125, e2018JF004961, https://doi.org/10.1029/2018JF004961 2020b.

Barnhart, K. R., Tucker, G. E., Doty, S., Shobe, C. M., Glade, R. C., Rossi, M. W., and Hill, M. C.: Inverting topography for landscape evolution model process representation: Part 2, calibration and validation, J. Geophys. Res.-Earth, 125, e2018JF004963, https://doi.org/10.1029/2018JF004963, 2020c.

Basili, V. R., Carver, J. C., Cruzes, D., Hochstein, L. M., Hollingsworth, J. K., Shull, F., and Zelkowitz, M. V.: Understanding the high-performance-computing community: A software engineer's perspective, IEEE Software, 25, 29-36, 2008.

Baxter, R., Hong, N. C., Gorissen, D., Hetherington, J., and Todorov, I.: The research software engineer, in: Digital Research Conference, Oxford, 2012.

Benureau, F. C. and Rougier, N. P.: Re-run, repeat, reproduce, reuse, replicate: transforming code into scientific contributions, Front. Neuroinf., 11, 69, https://doi.org/10.3389/fninf.2017.00069, 2018.

Bras, R., Tucker, G., and Teles, V.: Six myths about mathematical modeling in geomorphology, in: Prediction in Geomorphology, edited by: Wilcock, P. and Iverson, R., American Geophysical Union, 63-79, https://doi.org/10.1029/135GM06, 2003.

Brown, J., Knepley, M. G., and Smith, B. F.: Run-time extensibility and librarization of simulation software, Comput. Sci. Eng., 17, 38-45, 2014. 
Bryan, J.: Excuse me, do you have a moment to talk about version control?, Am. Stat., 72, 20-27, 2018.

Campbell, K., Overeem, I., and Berlin, M.: Taking it to the streets: the case for modeling in the geosciences undergraduate curriculum, Comput. Geosci., 53, 123-128, 2013.

Campforts, B., Shobe, C. M., Steer, P., Vanmaercke, M., Lague, D., and Braun, J.: HyLands 1.0: a hybrid landscape evolution model to simulate the impact of landslides and landslide-derived sediment on landscape evolution, Geosci. Model Dev., 13, 38633886, https://doi.org/10.5194/gmd-13-3863-2020, 2020.

Carriere, A., Le Bouteiller, C., Tucker, G. E., Klotz, S., and Naaim, M.: Impact of vegetation on erosion: Insights from the calibration and test of a landscape evolution model in alpine badland catchments, Earth Surf. Proc. Land., 45, 1085-1099, 2020.

Chen, X., Dallmeier-Tiessen, S., Dasler, R., Feger, S., Fokianos, P., Gonzalez, J. B., Hirvonsalo, H., Kousidis, D., Lavasa, A., Mele, S., Rodriguez, D. R., Šimko, T., Smith, T., Trisovic, A., Trzcinska, A., Tsanaktsidis, I., Zimmermann, M., Cranmer, K., Heinrich, L., Watts, G., Hildreth, M., Lloret Iglesias, L., LassilaPerini, K., and Neubert, S.: Open is not enough, Nature Phys., 15, 113-119, 2019.

Chue Hong, N. P., Katz, D. S., Barker, M., Lamprecht, A.-L., Martinez, C., Psomopoulos, F.E., Harrow, J., Castro, L.J., Gruenpeter, M., Martinez, P. A., Honeyman, T., Struck, A., Lee, A., Loewe, A., van Werkhove, B., Jones, C., Garijo, D., Plomp, E., Genova, F., Shanahan, H., Leng, J., Hellström, M., Sandström, M., Sinha, M., Kuzak, M., Herterich, P., Zhang, Q., Islam, S., Sansone, S.-A., Pollard, T., Atmojo, U.D., Williams, A., Czerniak, A., Niehues, A., Fouilloux, A.C., Desinghu, B., Goble, C., Richard, C., Gray, C., Erdmann, C., Nüst, D., Tartarini, D., Ranguelova, E., Anzt, H., Todorov, I., McNally, J., Moldon, J., Burnett, J., Garrido-Sánchez, J., Belhajjame, K., Sesink, L., Hwang, L., Tovani-Palone, M. R., Wilkinson, M.D., Servillat, M., Liffers, M., Fox, M., Miljković, N., Lynch, N., Martinez Lavanchy, P., Gesing, S., Stevens, S., Martinez Cuesta, S., Peroni, S., Soiland-Reyes, S., Bakker, T., Rabemanantsoa, T., Sochat, V., and Yehudi, Y.: FAIR principles for research software (FAIR4RS principles), Research Data Alliance, https://doi.org/10.15497/RDA00065, 2021.

Clune, T. and Rood, R.: Software testing and verification in climate model development, IEEE Software, 28, 49-55, 2011.

Eghbal, N.: Roads and Bridges: The Unseen labor behind our digital infrastructure, Tech. rep., Ford Foundation, 143 pp., 2016.

Epperly, T. G., Kumfert, G., Dahlgren, T., Ebner, D., Leek, J., Prantl, A., and Kohn, S.: High-performance language interoperability for scientific computing through Babel, Int. J. High Perform. C., 26, 260-274, 2012.

ESMF Joint Specification Team: Earth System Modeling Framework ESMF Reference Manual for Fortran, Version 8.2.0, Earth System Modeling Framework, https://earthsystemmodeling.org/ docs/release/latest/ESMF_refdoc/ (last access: 11 February 2022), 2021.

Fan, X., Scaringi, G., Korup, O., West, A. J., Westen, C. J., Tanyas, H., Hovius, N., Hales, T. C., Jibson, R. W., Allstadt, K. E., Zhang, L., Evans, S. G., Xu, C., Li, G., Pei, X., Xu, Q., and Huang, R.: Earthquake-Induced Chains of Geologic Hazards: Patterns, Mechanisms, and Impacts, Rev. Geophys., 57, 421503, https://doi.org/10.1029/2018RG000626, 2019.
Faulk, S., Loh, E., Van De Vanter, M. L., Squires, S., and Votta, L. G.: Scientific computing's productivity gridlock: How software engineering can help, Comput. Sci. Eng., 11, 30-39, 2009.

Fomel, S. and Claerbout, J. F.: Reproducible research, Comput. Sci. Eng., 11, 5-7, 2009.

Fox, T. A., Gao, M., Barchyn, T. E., Jamin, Y. L., and Hugenholtz, C. H.: An agent-based model for estimating emissions reduction equivalence among leak https://doi.org/10.1016/j.jclepro.2020.125237, 2020.

Glade, R. C., Shobe, C. M., Anderson, R. S., and Tucker, G. E.: Canyon shape and erosion dynamics governed by channelhillslope feedbacks, Geology, 47, 650-654, 2019.

Gray, H. J., Shobe, C. M., Hobley, D. E., Tucker, G. E., Duvall, A. R., Harbert, S. A., and Owen, L. A.: Off-fault deformation rate along the southern San Andreas fault at Mecca Hills, southern California, inferred from landscape modeling of curved drainages, Geology, 46, 59-62, 2017.

Groenenberg, R. M., Hodgson, D. M., Prelat, A., Luthi, S. M., and Flint, S. S.: Flow-deposit interaction in submarine lobes: Insights from outcrop observations and realizations of a process-based numerical model, J. Sediment. Res., 80, 252-267, 2010.

Guest, O. and Martin, A. E.: How computational modeling can force theory building in psychological science, Perspect. Psychol. Sci., 16, 789-802, https://doi.org/10.1177/1745691620970585, 2020.

Hannay, J. E., MacLeod, C., Singer, J., Langtangen, H. P., Pfahl, D., and Wilson, G.: How do scientists develop and use scientific software?, in: 2009 ICSE Workshop on Software Engineering for Computational Science and Engineering, 1-8, 2009.

Harpham, Q., Hughes, A., and Moore, R.: Introductory overview: The OpenMI 2.0 standard for integrating numerical models, Environ. Modell. Softw., 122, 104549, https://doi.org/10.1016/j.envsoft.2019.104549, 2019.

Hastings, J., Haug, K., and Steinbeck, C.: Ten recommendations for software engineering in research, GigaScience, 3, 31, https://doi.org/10.1186/2047-217X-3-31, 2014.

Hatton, L.: The T-experiments: errors in scientific software, in: Quality of Numerical Software, edited by: Boisvert, R. F., IFIP Advances in Information and Communication Technology. Springer, Boston, MA, 12-31, https://doi.org/10.1007/9781-5041-2940-4_2, 1997.

Hatton, L.: The chimera of software quality, Computer, 40, 104103, 2007.

Heaton, D. and Carver, J. C.: Claims about the use of software engineering practices in science: A systematic literature review, Comm. Com. Inf. Sc., 67, 207-219, 2015.

Hestenes, D.: Modeling Methodology for Physics Teachers: Proceedings of the International Conference on Undergraduate Physics Education, College Park, August 1996.

Hobley, D. E. J., Adams, J. M., Nudurupati, S. S., Hutton, E. W. H., Gasparini, N. M., Istanbulluoglu, E., and Tucker, G. E.: Creative computing with Landlab: an open-source toolkit for building, coupling, and exploring two-dimensional numerical models of Earth-surface dynamics, Earth Surf. Dynam., 5, 21-46, https://doi.org/10.5194/esurf-5-21-2017, 2017.

Hoch, J. M. and Trigg, M. A.: Advancing global flood hazard simulations by improving comparability, benchmarking, and integration of global flood models, Environ. Res. Lett., 14, 034001, https://doi.org/10.1088/1748-9326/aaf3d3, 2019. 
Hoch, J. M., Eilander, D., Ikeuchi, H., Baart, F., and Winsemius, H. C.: Evaluating the impact of model complexity on flood wave propagation and inundation extent with a hydrologichydrodynamic model coupling framework, Nat. Hazards Earth Syst. Sci., 19, 1723-1735, https://doi.org/10.5194/nhess-191723-2019, 2019.

Howison, J. and Herbsleb, J. D.: Scientific software production: incentives and collaboration, in: Proceedings of the ACM 2011 conference on Computer supported cooperative work, 513-522, 2011.

Hsu, L., Martin, R. L., McElroy, B., Litwin-Miller, K., and Kim, W.: Data management, sharing, and reuse in experimental geomorphology: Challenges, strategies, and scientific opportunities, Geomorphology, 244, 180-189, 2015.

Hut, R., Drost, N., van de Giesen, N., van Werkhoven, B., Abdollahi, B., Aerts, J., Albers, T., Alidoost, F., Andela, B., Camphuijsen, J., Dzigan, Y., van Haren, R., Hutton, E., Kalverla, P., van Meersbergen, M., van den Oord, G., Pelupessy, I., Smeets, S., Verhoeven, S., de Vos, M., and Weel, B.: The eWaterCycle platform for Open and FAIR Hydrological collaboration, Geosci. Model Dev. Discuss. [preprint], https://doi.org/10.5194/gmd2021-344, in review, 2021.

Hutton, E. and Piper, M.: csdms/babelizer: (v0.3.8), Zenodo [code], https://doi.org/10.5281/zenodo.4985181, 2021.

Hutton, E. W. and Syvitski, J. P.: Sedflux 2.0: An advanced processresponse model that generates three-dimensional stratigraphy, Comput. Geosci., 34, 1319-1337, 2008.

Hutton, E. W., Piper, M. D., and Tucker, G. E.: The Basic Model Interface 2.0: A standard interface for coupling numerical models in the geosciences, J. Open Source Softw., 5, 2317, https://doi.org/10.21105/joss.02317, 2020.

Hutton, E., Barnhart, K., Hobley, D., Tucker, G., Nudurupati, S. S., Adams, J., Gasparini, N. M., Shobe, C., Strauch, R., Knuth, J., Mouchene, M., Lyons, N., Litwin, D., Glade, R., Cipolla, G., Manaster, A., alangston, Thyng, K., and Rengers, F.: landlab/landlab: Mrs. Weasley (v2.0.1), Zenodo [code], https://doi.org/10.5281/zenodo.3776837, 2020b.

Hutton, E., Piper, M., Gan, T., Kettner, A. J., and Drost, N.: csdms/pymt: (v1.3.1), Zenodo [code], https://doi.org/10.5281/zenodo.4985222, 2021.

Hwang, L., Fish, A., Soito, L., Smith, M., and Kellogg, L. H.: Software and the scientist: Coding and citation practices in geodynamics, Earth pace Sci., 4, 670-680, 2017.

Istanbulluoglu, E. and Bras, R. L.: Vegetation-modulated landscape evolution: Effects of vegetation on landscape processes, drainage density, and topography, J. Geophys. Res., 110, F02012, https://doi.org/10.1029/2004JF000249, 2005.

Jacobs, C. T., Gorman, G. J., Rees, H. E., and Craig, L. E.: Experiences with efficient methodologies for teaching computer programming to geoscientists, J. Geosci. Educ., 64, 183-198, 2016.

Johanson, A. and Hasselbring, W.: Software engineering for computational science: Past, present, future, Comput. Sci. Eng., 20, 90-109, https://doi.org/10.1109/MCSE.2018.021651343, 2018.

Kanewala, U. and Bieman, J. M.: Testing scientific software: A systematic literature review, Inform. Softw. Tech., 56, 1219-1232, 2014.

Katz, D. S., Gruenpeter, M., and Honeyman, T.: Taking a fresh look at FAIR for research software, Patterns, 2, 3, https://doi.org/10.1016/j.patter.2021.100222, 2021.
Kellogg, L. H., Hwang, L. J., Gassmöller, R., Bangerth, W., and Heister, T.: The role of scientific communities in creating reusable software: Lessons from geophysics, Comput. Sci. Eng., 21, 25-35, 2018.

Kelly, D. F.: A software chasm: Software engineering and scientific computing, IEEE Software, 24, 120-119, 2007.

Kettner, A. J.: CSDMS by the numbers, https://csdms.colorado.edu/ wiki/CSDMS_in_numbers, last access: 14 February 2022.

King, J. and South, J.: Reimagining the role of technology in higher education: A supplement to the national education technology plan, US Department of Education, Office of Educational Technology, 2017.

Krafczyk, M., Shi, A., Bhaskar, A., Marinov, D., and Stodden, V.: Scientific Tests and Continuous Integration Strategies to Enhance Reproducibility in the Scientific Software Context, in: Proceedings of the 2nd International Workshop on Practical Reproducible Evaluation of Computer Systems, 23-28, 2019.

Kuehl, S. A., Alexander, C. R., Blair, N. E., Harris, C. K., Marsaglia, K. M., Ogston, A. S., Orpin, A. R., Roering, J. J., Bever, A. J., Bilderback, E. L., Carter, L., Cerovski-Darriau, C., Childress, L. B., Corbett, D. R., Hale, R. P., Leithold, E. L., Litchfield, N., Moriarty, J. M., Page, M. J., Pierce, L. E. R., Upton, P., and Walsh, J. P.: A source-to-sink perspective of the Waipaoa River margin, Earth-Sci. Rev., 153, 301-334, 2016.

Lai, J. and Anders, A. M.: Modeled postglacial landscape evolution at the southern margin of the Laurentide Ice Sheet: hydrological connection of uplands controls the pace and style of fluvial network expansion, J. Geophys. Res.-Earth, 123, 967-984, 2018.

Lamprecht, A.-L., Garcia, L., Kuzak, M., Martinez, C., Arcila, R., Martin Del Pico, E., Dominguez Del Angel, V., Van De Sandt, S., Ison, J., Martinez, P. A., McQuilton, P., Valencia, A., Harrow, J., Psomopoulos, F., Gelpi, J. L., Chue Hong, N., Goble, C., and Capella-Gutierrez, S.: Towards FAIR principles for research software, Data Science, 3, 37-59, 2020.

Langston, A. L. and Tucker, G. E.: Developing and exploring a theory for the lateral erosion of bedrock channels for use in landscape evolution models, Earth Surf. Dynam., 6, 1-27, https://doi.org/10.5194/esurf-6-1-2018, 2018.

Lathrop, S., Folk, M., Katz, D. S., McInnes, L. C., and Terrel, A.: Introduction to Accelerating Scientific Discovery With Reusable Software, Comput. Sci. Eng., 21, 5-7, 2019.

Lawrence, K. A., Zentner, M., Wilkins-Diehr, N., Wernert, J. A., Pierce, M., Marru, S., and Michael, S.: Science gateways today and tomorrow: positive perspectives of nearly 5000 members of the research community, Concurr. Comp.-Pract. E., 27, 42524268, 2015.

Leavesley, G., Lichty, R., Troutman, B., and Saindon, L.: Precipitation-runoff modeling system: User's manual, Vol. 83, U.S. Department of the Interior, 1983.

Leavesley, G., Restrepo, P. J., Markstrom, S., Dixon, M., and Stannard, L.: The modular modeling system (MMS): User's manual, US Geological Survey Open-File Report, 96, 1996.

LeVeque, R. J.: Python tools for reproducible research on hyperbolic problems, Comput. Sci. Eng., 11, 19-27, 2009.

LeVeque, R. J.: Top ten reasons to not share your code (and why you should anyway), Siam News, 46, 2013.

Litwin, D. G., Tucker, G. E., Barnhart, K. R., and Harman, C. J.: GroundwaterDupuitPercolator: A Landlab compo- 
nent for groundwater flow, J. Open Source Softw., 5, 1935, https://doi.org/10.21105/joss.01935, 2020.

Luettich, R. A., Westerink, J. J., Scheffner, N. W.: ADCIRC: an advanced three-dimensional circulation model for shelves, coasts, and estuaries, Report 1, Theory and methodology of ADCIRC2DD1 and ADCIRC-3DL, Technical Report, Coastal Engineering and Research Center and Engineer Research and Development Center, US Army Corps of Engineers, 1992.

Lyons, N., Albert, J., and Gasparini, N.: SpeciesEvolver: A Landlab component to evolve life in simulated landscapes, J. Open Source Softw., 5, 2066, https://doi.org/10.21105/joss.02066, 2020.

Manduca, C. A., Baer, E., Hancock, G., Macdonald, R. H., Patterson, S., Savina, M., and Wenner, J.: Making undergraduate geoscience quantitative, Eos T. Am. Geophys. Un., 89, 149-150, 2008

Mariotti, G.: Marsh channel morphological response to sea level rise and sediment supply, Estuar. Coast. Shelf S., 209, 89-101, 2018.

Markstrom, S. L., Regan, R. S., Hay, L. E., Viger, R. J., Webb, R. M., Payn, R. A., and LaFontaine, J. H.: PRMS-IV, the precipitation-runoff modeling system, version 4, US Geological Survey Techniques and Methods, book 6, chap. B7, 158 pp., https://doi.org/10.3133/tm6B7, ISSN 2328-7055, 2015.

Miller, G.: A scientist's nightmare: Software problem leads to five retractions, Science, 314, 1856-1857, https://doi.org/10.1126/science.314.5807.1856, 2006.

Morin, A., Urban, J., Adams, P. D., Foster, I., Sali, A., Baker, D., and Sliz, P.: Shining light into black boxes, Science, 336, 159$160,2012$.

Nanthaamornphong, A. and Carver, J. C.: Test-Driven Development in scientific software: a survey, Software Qual. J., 25, 343-372, 2017.

Nanthaamornphong, A. and Carver, J. C.: Test-Driven Development in HPC Science: A Case Study, Comput. Sci. Eng., 20, 98-113, 2018.

Nasr-Azadani, M., Hall, B., and Meiburg, E.: Polydisperse turbidity currents propagating over complex topography: comparison of experimental and depth-resolved simulation results, Comput. Geosci., 53, 141-153, 2013.

Nguyen-Hoan, L., Flint, S., and Sankaranarayana, R.: A survey of scientific software development, in: Proceedings of the 2010 ACM-IEEE International Symposium on Empirical Software Engineering and Measurement, 1-10, 2010.

NRC: A Visioin for NSF Earth Sciences 2020-2030: Earth in Time, The National Academies Press, https://doi.org/10.17226/25761, 2020 .

Overeem, I., Berlin, M. M., and Syvitski, J. P.: Strategies for integrated modeling: The Community Surface Dynamics Modeling System example, Environ. Modell. Softw., 39, 314-321, 2013.

Peckham, S. D., Hutton, E. W., and Norris, B.: A component-based approach to integrated modeling in the geosciences: The design of CSDMS, Comput. Geosci., 53, 3-12, 2013.

Pelletier, J. D., Barron-Gafford, G. A., Guttierez-Jurado, H., Hinckley, E.-L. S., Istanbulluoglu, E., McGuire, L. A., Niu, G.Y., Poulos, M. J., Rasmussen, C., Richardson, P., Swetnam, T. L., and Tucker, G. E.: Which way do you lean? Using slope aspect variations to understand Critical Zone processes and feedbacks, Earth Surf. Proc. Land., 43, 1133-1154, https://doi.org/10.1002/esp.4306, 2017.
Peng, R. D.: Reproducible research in computational science, Science, 334, 1226-1227, 2011.

Pfeiffer, A. M., Barnhart, K. R., Czuba, J. A., and Hutton, E. W. H.: NetworkSedimentTransporter: A Landlab component for bed material transport through river networks, J. Open Source Softw., 5, 2341, https://doi.org/10.21105/joss.02341, 2020.

Pinto, G., Wiese, I., and Dias, L. F.: How do scientists develop scientific software? an external replication, in: 2018 IEEE 25th International Conference on Software Analysis, Evolution and Reengineering (SANER), 582-591, 2018.

Pipitone, J. and Easterbrook, S.: Assessing climate model software quality: a defect density analysis of three models, Geosci. Model Dev., 5, 1009-1022, https://doi.org/10.5194/gmd-5-1009-2012, 2012.

Poisot, T.: Best publishing practices to improve user confidence in scientific software, Ideas in Ecology and Evolution, 8, 5054,https://doi.org/10.4033/iee.2015.8.8.f, 2015.

Post, D.: The changing face of scientific and engineering computing, Comput. Sci. Eng., 15, 4-6, 2013.

Post, D. E. and Votta, L. G.: Computational science demands a new paradigm, Phys. Today, 58, 35-41, 2005.

Prabhu, P., Kim, H., Oh, T., Jablin, T. B., Johnson, N. P., Zoufaly, M., Raman, A., Liu, F., Walker, D., Zhang, Y., Ghosh, S., August, D. I., Huang, J., and Beard, S.: A survey of the practice of computational science, in: SC'11: Proceedings of 2011 International Conference for High Performance Computing, Networking, Storage and Analysis, 1-12, 2011.

Ratliff, K. M., Hutton, E. H., and Murray, A. B.: Exploring Wave and Sea-Level Rise Effects on Delta Morphodynamics With a Coupled River-Ocean Model, J. Geophys. Res.-Earth, 123, 2887-2900, 2018.

Reed, D. A., Bajcsy, R., Fernandez, M. A., Griffiths, J.-M., Mott, R. D., Dongarra, J., Johnson, C. R., Inouye, A. S., Miner, W., Matzke, M. K., and Ponick, T. L.: Computational Science: Ensuring America's Competitiveness, President's Information Technology Advisory Committee, National Coordination Office for Information Technology Research \& Development, US government technical report, 2005.

Regan, R. S., Markstrom, S. L., Hay, L. E., Viger, R. J., Norton, P. A., Driscoll, J. M., and LaFontaine, J. H.: Description of the national hydrologic model for use with the precipitation-runoff modeling system (PRMS), Tech. rep., US Geological Survey, 2018.

Regan, R. S., Juracek, K. E., Hay, L. E., Markstrom, S., Viger, R. J., Driscoll, J. M., LaFontaine, J., and Norton, P. A.: The US Geological Survey National Hydrologic Model infrastructure: Rationale, description, and application of a watershed-scale model for the conterminous United States, Environ. Modell. Softw., 111, 192-203, 2019.

Reitman, N. G., Mueller, K. J., Tucker, G. E., Gold, R. D., Briggs, R. W., and Barnhart, K. R.: Offset Channels May Not Accurately Record Strike-Slip Fault Displacement: Evidence From Landscape Evolution Models, J. Geophys. Res.-Sol. Ea., 124, 1342713451, 2019.

Robinson, D. T., Di Vittorio, A., Alexander, P., Arneth, A., Barton, C. M., Brown, D. G., Kettner, A., Lemmen, C., O'Neill, B. C., Janssen, M., Pugh, T. A. M., Rabin, S. S., Rounsevell, M., Syvitski, J. P., Ullah, I., and Verburg, P. H.: Modelling feedbacks between human and natural processes in the land system, 
Earth Syst. Dynam., 9, 895-914, https://doi.org/10.5194/esd-9895-2018, 2018.

Roy, S., Koons, P., Upton, P., and Tucker, G.: Dynamic links among rock damage, erosion, and strain during orogenesis, Geology, 44, 583-586, 2016.

Schmid, M., Ehlers, T. A., Werner, C., Hickler, T., and FuentesEspoz, J.-P.: Effect of changing vegetation and precipitation on denudation - Part 2: Predicted landscape response to transient climate and vegetation cover over millennial to million-year timescales, Earth Surf. Dynam., 6, 859-881, https://doi.org/10.5194/esurf-6-859-2018, 2018.

Schwab, M., Karrenbach, N., and Claerbout, J.: Making scientific computations reproducible, Comput. Sci. Eng., 2, 61-67, 2000.

Scott, S.: ESIP Software Assessment Guidelines, Earth Science Information Partners, 53 pp., 2017.

Shchepetkin, A. F. and McWilliams, J. C.: The regional oceanic modeling system (ROMS): a split-explicit, free-surface, topography-following-coordinate oceanic model, Ocean Modell., 9, 347-404, 2005.

Shobe, C. M., Tucker, G. E., and Barnhart, K. R.: The SPACE 1.0 model: a Landlab component for 2-D calculation of sediment transport, bedrock erosion, and landscape evolution, Geosci. Model Dev., 10, 4577-4604, https://doi.org/10.5194/gmd-104577-2017, 2017.

Singer, S. R., Nielsen, N. R., and Schweingruber, H. A. (Eds.): Discipline-based education research: Understanding and improving learning in undergraduate science and engineering, National Academies Press, 2012.

Singh Chawla, D.: The unsung heroes of scientific software, Nature News, 529, 115-116, 2016.

Smith, A. M., Niemeyer, K. E., Katz, D. S., Barba, L. A., Githinji, G., Gymrek, M., Huff, K. D., Madan, C. R., Mayes, A. C., Moerman, K. M., Prins, P., Ram, K., Rokem, A., Teal, T. K., Valls Guimera, R., and Vanderplas, J. T.: Journal of Open Source Software (JOSS): design and first-year review, PeerJ Comput. Sci., 4 , e147, https://doi.org/10.7717/peerj-cs.147, 2018.

Steckler, M. S., Hutton, E., Ologan, D., Tucker, G. E., Grall, C., and Gurcay, S.: Developing Sequence Stratigraphic Modeling in Landlab to improve understanding of the tectonics in the Gulf of Kusadasi, Turkey, AGUFM, 2019, EP21D-2227, 2019.

Stodden, V., Borwein, J., and Bailey, D. H.: Setting the default to reproducible, computational science research, SIAM News, 46, 4-6, 2013.

Stodden, V., Krafczyk, M. S., and Bhaskar, A.: Enabling the verification of computational results: An empirical evaluation of computational reproducibility, in: Proceedings of the First International Workshop on Practical Reproducible Evaluation of Computer Systems, 1-5, 2018.

Stoica, M.: Scientific Variables Ontology and Associated Tools, https://github.com/mariutzica/ScientificVariablesOntology (last access: 11 February 2022), 2020.

Stoica, M. and Peckham, S. D.: An Ontology Blueprint for Constructing Qualitative and Quantitative Scientific Variables, in: International Semantic Web Conference (P\&D/Industry/BlueSky), 2018.

Stoica, M. and Peckham, S.: Incorporating New Concepts Into the Scientific Variables Ontology, in: 2019 15th International Conference on eScience (eScience), 539-540, 2019a.
Stoica, M. and Peckham, S.: The Scientific Variables Ontology: A blueprint for custom manual and automated creation and alignment of machine-interpretable qualitative and quantitative variable concepts, http://pittmodelingconference.sci.pitt.edu (last access: 11 February 2022), 2019b.

Strauch, R., Istanbulluoglu, E., Nudurupati, S. S., Bandaragoda, C., Gasparini, N. M., and Tucker, G. E.: A hydroclimatological approach to predicting regional landslide probability using Landlab, Earth Surf. Dynam., 6, 49-75, https://doi.org/10.5194/esurf6-49-2018, 2018.

SVO: Scientific Variables Ontology, http://geoscienceontology.org, last access: 26 October 2020.

Taschuk, M. and Wilson, G.: Ten simple rules for making research software more robust, PLoS Comput. Biol., 13, e1005412, https://doi.org/10.1371/journal.pcbi.1005412. 2017.

Thyng, K. M., Greene, C. A., Zimmerle, H. M., and DiMarco, S. F.: True Colors of Oceanography: Guidelines for Effective and Accurate Colormap Selection, Oceanography, 29, 9-13, https://doi.org/10.5670/oceanog.2016.66, 2016.

Tucker, G. E.: Python code and documentation for island simulation example, Zenodo [code], https://doi.org/10.5281/zenodo.6049847, 2022.

Tucker, G. E., Lancaster, S. T., Gasparini, N. M., and Bras, R. L.: The Channel-Hillslope Integrated Landscape Development Model (CHILD), in: Landscape Erosion and Evolution Modeling, edited by: Harmon, R. S. and Doe, W. W., Kluwer Press, Dordrecht, 349-388, 2001.

Turk, M. J.: Scaling a code in the human dimension, in: Proceedings of the Conference on Extreme Science and Engineering Discovery Environment: Gateway to Discovery, 1-7, 2013.

Virtanen, P., Gommers, R., Oliphant, T. E., Haberland, M., Reddy, T., Cournapeau, D., Burovski, E., Peterson, P., Weckesser, W., Bright, J., van der Walt, S. J., Brett, M., Wilson, J., Jarrod Millman, K., Mayorov, N., Nelson, A. R. J., Jones, E., Kern, R., Larson, E., Carey, C., Polat, İ., Feng, Y., Moore, E. W., Vand erPlas, J., Laxalde, D., Perktold, J., Cimrman, R., Henriksen, I., Quintero, E. A., Harris, C. R., Archibald, A. M., Ribeiro, A. H., Pedregosa, F., van Mulbregt, P., and SciPy 1.0 Contributors: SciPy 1.0: Fundamental Algorithms for Scientific Computing in Python, Nat. Methods, 17, 261-272, https://doi.org/10.1038/s41592-019-0686-2, 2020.

Voinov, A., Fitz, C., Boumans, R., and Costanza, R.: Modular ecosystem modeling, Environ. Modell. Softw., 19, 285-304, 2004.

W3C Working Group: Best Practice Recipes for Publishing RDF Vocabularies, https://www.w3.org/TR/swbp-vocab-pub/ (last access: 26 October 2020), 2008.

Wiese, I. S., Polato, I., and Pinto, G.: Naming the Pain in Developing Scientific Software, IEEE Software, 37, 75-82, 2019.

Wilkinson, M. D., Dumontier, M., Aalbersberg, I. J., Appleton, G., Axton, M., Baak, A., Blomberg, N., Boiten, J.-W., da Silva Santos, L. B., Bourne, P. E., Bouwman, J., Brookes, A. J., Clark, T., Crosas, M., Dillo, I., Dumon, O., Edmunds, S., Evelo, C. T., Finkers, R., Gonzalez-Beltran, A., Gray, Alasdair, J. G., Groth, P., Goble, C., Grethe, J. S., Heringa, J., 't Hoen, P. A. C., Hooft, R., Kuhn, T., Kok, R., Kok, J., Lusher, S. J., Martone, M. E., Mons, A., Packer, A. L., Persson, B., Rocca-Serra, P., Roos, M., van Schaik, R., Sansone, S.-A., Schultes, E., Sengstag, T., Slater, T., Strawn, G., Swertz, M. A., Thompson, M., van der Lei, J., van 
Mulligen, E., Velterop, J., Waagmeester, A., Wittenburg, P., Wolstencroft, K., Zhao, J., and Mons, B.: The FAIR Guiding Principles for scientific data management and stewardship, Sci. Data, 3, 160018, https://doi.org/10.1038/sdata.2016.18, 2016.

Wilson, G., Aruliah, D. A., Brown, C. T., Hong, N. P. C., Davis, M., Guy, R. T., Haddock, S. H., Huff, K. D., Mitchell, I. M., Plumbley, M. D., Waugh, B., White, E. P., and Wilson, P.: Best practices for scientific computing, PLoS biology, 12, e1001745, https://doi.org/10.1371/journal.pbio.1001745, 2014.
Wilson, G., Bryan, J., Cranston, K., Kitzes, J., Nederbragt, L., and Teal, T. K.: Good enough practices in scientific computing, PLoS Comput. Biol., 13, e1005510, https://doi.org/10.1371/journal.pcbi.1005510, 2017.

Wilson, G. V.: Where's the real bottleneck in scientific computing?, Am. Sci., 94, 5-6, 2006. 